
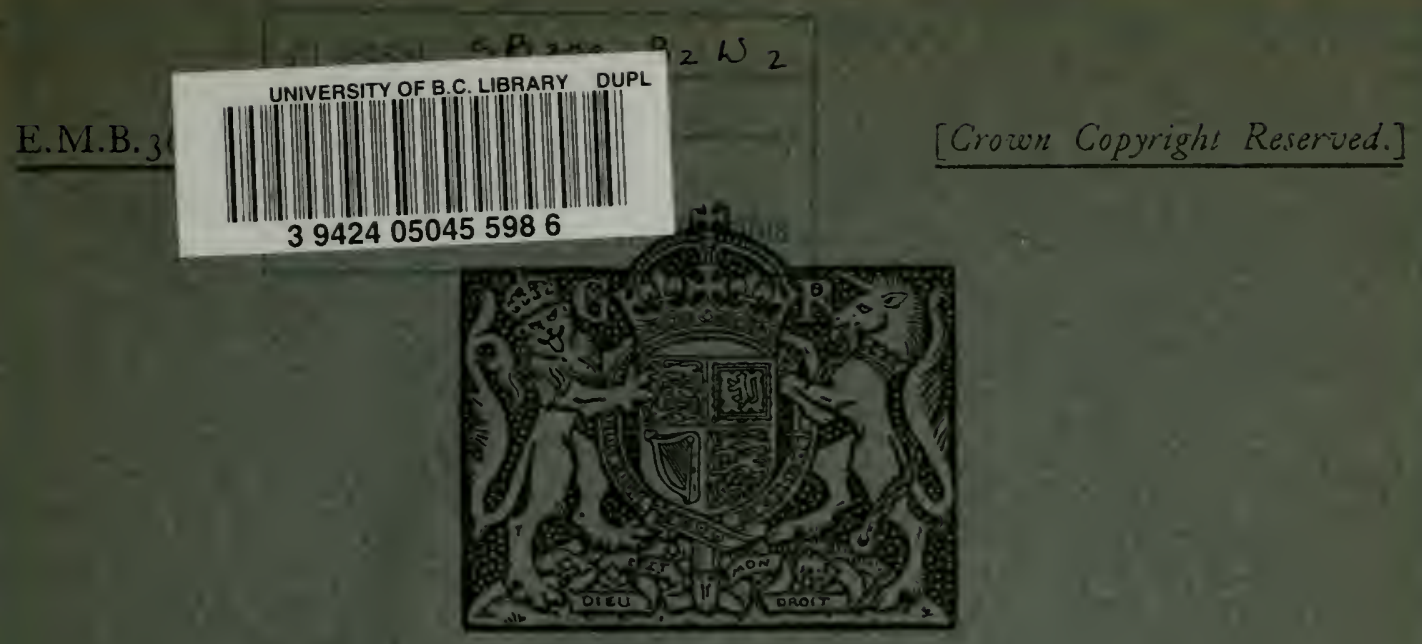

\title{
THE BEHAVIOUR AND DISEASES
} OF- THE BANANA IN STORAGE AND TRANSPORT

\author{
By
}

CLAUDE W. WARDLAW, Ph.D., D.Sc., F.R.S.E., Pathologist, and

LAURENCE P. McGUIRE, Ph.D., M.Sc., D.I.C., Physiologist, Low Temperature Station, Imperial College of Tropical Agriculture, Trinidad, B.W.I.

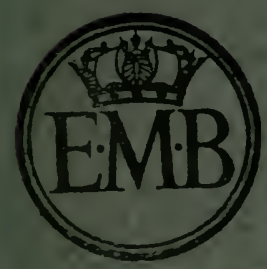

JANUARY, I93I

\section{LONDON :}

PRINTED AND PUBLISHED BY HIS MAJESTY'S STATIONERY OFFICE. Price Is. od. Net. 




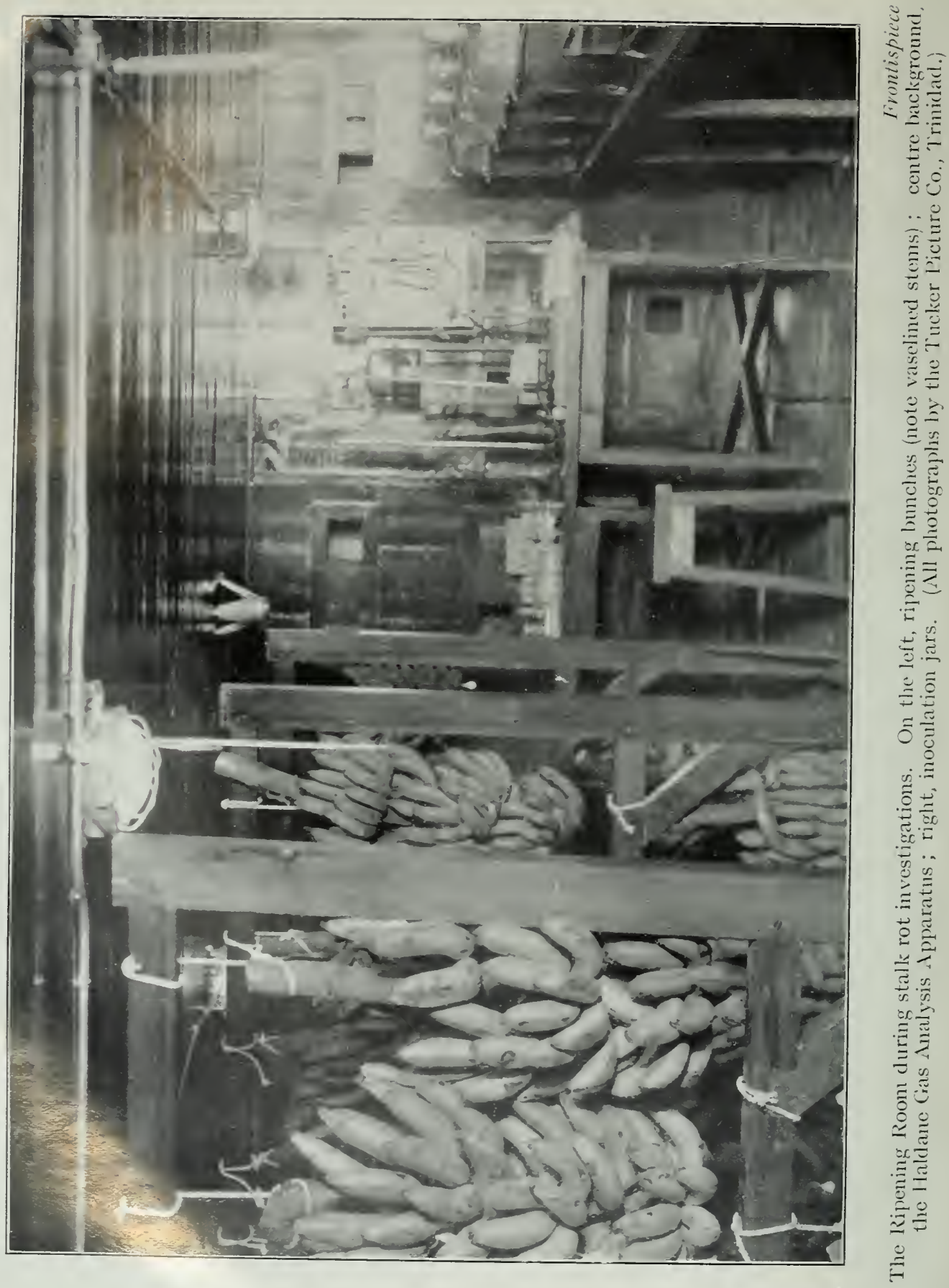




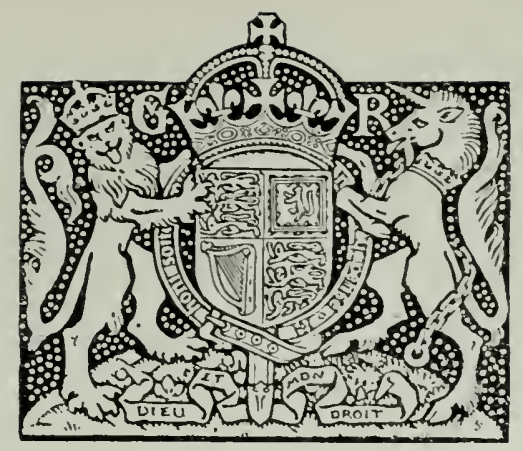

\section{THE BEHAVIOUR AND DISEASES OF THE BANANA IN STORAGE AND TRANSPORT}

By

CLAUDE W. WARDLAW, Ph.D., D.Sc., F.R.S.E., Pathologist, and

LAUREnCE P. McGUiRE, Ph.D., M.Sc., D.I.C., Physiologist, Low Temperature Station, Imperial College of Tropical Agriculture, Trinidad, B.IV.I.

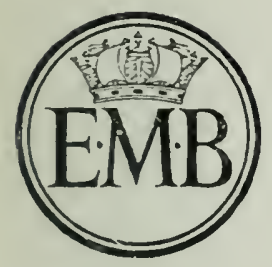

JANUARY, I93I

PRINIED AND PUBIISHED BY HIS MAIESTY'S S'TATIONERY OFFICE 'To be purchased directly from H.M. S'TATIONERY OFFICE at the following addresses : Adastral House. Kingsway, London, W.C.2 ; I20, George Strect. Edinburgh ;

York Street, Manchester: I, St. Andrew's Crescent, Cardiff;

I 5 , Donegall Square West. Belfast :

or through any. Bookseller.

$193 \mathrm{I}$.

Price is. od. Net. 
Digitized by the Internet Archive in 2010 with funding from University of British Columbia Library 


\section{PREFACE.}

THIS Report, the second prepared by Dr. Wardlaw and Dr. McGuire to be issued in this series by the Empire Marketing Board, carries one step further an interesting scientific attempt to defeat what is probably the most serious menace to the banana crop in the British West Indies.

Panama Disease, which first appeared in Central America in 1903, has caused heary losses in the West Indies and has forced the abandonment of thousands of acres of plantations. The problem is a serious one, for the value of exports of bananas from the British West Indies amounts on the average to about $f 2,000.000$ annually.

With the financial help of the Empire Markeiing Board, a threefold attack on the disease is in progress at the Imperial College of Tropical Agriculture in Trinidad. In the first place a study is being made of the fungus, Fusarimm Cubense, which causes the disease. A tour of the banana-producing countries of the Caribbean, the results of which were published by the Board in July, 1929,* was undertaken by I)r. Wardlaw and Dr. McGuire in order to study the factors affecting the distribution and behaviour of the disease. The authors of this Report were able to establish an important fact; namely, that in many cases the sickness of banana stools which led to the abandonment of plantations was not directly due to Panama I)isease, but could be traced to other factors, such as unsuitable soil and poor drainage.

Secondly, an attempt is being made to breed a new variety of banana resistant to Panama Disease, but retaining the valuable commercial qualities which make the Gros Michel the predominant variety in the West Indies. Strains immune to Panama Disease hare been produced and the most promising of these have been selected for further experimentation.

The third line of attack is dealt with in this keport. It is an attempt to out-flank the enemy by tackling the difficulties which prevent West Indian planters from cultivating commercial varieties 
of bananas other than the Gros Michel. The most important advantage of the Gros Michel is its ability to travel in " naked " bunches, uncrated, and to stand up well to ocean transport. Other varieties, though equally popular with the consumer, are not so well adapted for transport. If the transport difficulties could be overcome it is clear that these other varieties, e.g., Cavendish and Lacatan, which are not susceptible to Panama Disease, could be substituted by the grower.

A careful study, therefore, of the behaviour in storage and transport of several varieties (Cavendish, Congo, Lacatan, Bumulan, Giant Fig, etc.) has been made by Dr. Wardlaw and Dr. McGuire. For the purposes of this investigation a Low Temperature Research Station has been erected by the Empire Marketing Board at the Imperial College in Trinidad, and the results of the first storage and ripening trials are given in this Report.

The Report also contains several definite recommendations as to the shipping and storage of bananas calculated to reduce wastage in transit, and a number of practical suggestions are included which should prove of value to the banana trade. I have pleasure in expressing my sense of the value of this work and in commending its study to all concerned.

\section{T. IORUMIIONI) SHIELS, Chairman of the Research Grants Committee.}

Empire Marketing Board,

December, 1930. 


\section{CON'TENTS.}

Covering Letter from Alithors.

1. Introduction

2. Preliminary Storage Trial: .

3. Bulk storage Trials

4 Observations on Fungi at the Low Temperature Station

5. Application to Transport

tS

6. Crated Fruit

7. Concluding Observations 58

Apperitix.

Banan! Lrmit Disease's . . . . . 



\section{INDEX OF ILLUSTRATIONS.}

Frontispiece-The ripening room during stalk rot investigations. On the left, ripening bunches (note vasclined stems) ; centre background, the Haldane Gas Analysis Apparatus ; right, inoculation jars. (All photographs by the Tucker Picture Co., Trinidad.)

Fig.

1. A Gros Michel bunch. Note symmetry . . . . . . . 13

2. The Congo . . . . . . . . . . 13

3. The Cavendish variety-good Trinidad fruit; left, green; right, advancing maturity . . . . . . . .

4. The Lacatan; left, green ; right, same buch during ripening. Note departure from original symmetry, and premature ripening in bottom hand due to break in stem.

5. The Bumulan; characteristic ripening bunches. Note the peculiar departure from symmetry . . . . . . . . 16

6. The Hybrid, G $\mathrm{II} \times \mathrm{B}_{2}$. . . . . . . . . . 17

7. The vaseline treatment. A, D, and F vaselined; B. C, and E not raselined . . . . . . . . . 19

Sci 9. Stages in finger-dropping due to late maturity in the Gros Michel . . 20

10. A bulk storage trial of the Cavendish variety . . . . . 24

11. Ripening of the Cavendish variety shown in Fig. 10. Note efficacy of carefully vaselined stems . . . . . . . . . . .

12. A comparison of carefully and carclessly vaselined stems after bulk storage $\left(1 \mathrm{~S}_{2}^{1}\right.$ days at $52 \cdot \overline{5}^{3} \mathrm{~F}$.)

13. Growth curves of Fungi at $78^{\circ} \mathrm{F},-82^{\circ} \mathrm{F}$. 1. Thielaviopsis; 2. Gloensporium (Strain B); 3. Phomopsis; 4. Glocosforium (Strain A); 5. Fusarium Sp; 6. Fusarium sp.

14. Growth curves at $55^{\circ}$ F. 1. Thiclaviopsis ; 2. Glocosporimm (Strain 13); 3. Phomopsis; 4. Glocosporium (Strain A); 5. Fusarium sp;

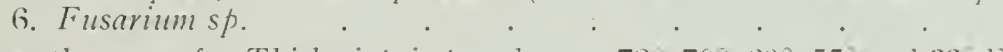

15. Growth curves for Thiclariopsis paradoxa at $78,70,60^{\circ}, 55$ and $32=1$.

16. Growth curves for Glocosporium musarmm (Strain A), at 78, 7(0. $60^{\circ}$ and $55^{\circ} \mathrm{F}$.

17. Disease effects produced by inoculating a cushion with Thichuropsis paradoxa

18. Advanced stage of infection resulting from a cushion inoculation with Thiclaziopsis paradoxa

19. Finger-chopping resulting from inoculating main stalk with Thidariopsis paradoxa. The shrunken stem and general disorganisattion of fingers are also shown 


\section{INDEX OF ILLUSTRATIONS-contimued.}

Fig.

20. Lesion produced on main-stalk by inoculation with Gloeosporium muscirum. Finger-stalk rot is also present on right hand fingers

21. Local lesion and stem splitting produced by an inoculation with Gloeosporium musarum

22. Finger-stalk rot produced by Gloeosporium musarum on wounded fingerstalks. Every second finger was left unwounded. Note fingerdropping on right and its commencement on left . . .

23. Finger-stalk and finger inoculations with Gloeosporium musurum. Every second finger was left unwounded, but most of the inoculations have given positive results .

24. Finger-stalk and finger inoculations with Gloeosporium masamm (Strain B). The skin was scratched before inoculation, and it will be seen that positive results were obtained in all but one finger end. Spores applied to uninjured tissue mid-way in each finger gave negative results.

25. Main-stalk rot (an early stage) produced by Botrodiplodia theobromae

26. Main-stalk rot produced by Phomopsis sp. .

27. Growth curves for Gloeosforium musurum at $7 \mathrm{~S}^{\circ}-82 \mathrm{~F}$. and $55^{\circ} \mathrm{F}$. (see text)

2S. Growth curves for Botrodiplodia theobromac at $78 \mathrm{~F}, 82 \mathrm{~F}$. and $55^{\circ} \mathrm{F}$.

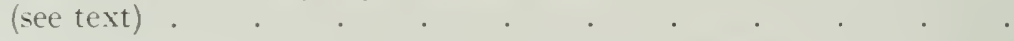

rated fruit: right, pre-cooled in bunch before cutting into hands and crating; left, bunch cut into hands before cooling (both crated with cooled packing material). Note striking difference 


\section{Imperial College of Tropical Agriculture. \\ Low Temperature Station, \\ Trinidad. B.W.I. 5th May, 1930}

The Empire Marketing Board,

2, Queen Anne's Gate Buildings,

London, S.W.1.

Gentlemen,

It is our pleasure to submit a report on the behaviour and diseases of the banana in storage and transport.

Our results have been rendered in a form readily accessible to practical laymen; to this end, occasional re-statements occur for the sake of greater clarity.

Our researches have been directed chiefly to the major problems of the Industry, namely :-

(1) The need for a substitute for the Gros Michel.

(2) The prevention of wastage in banana cargoes (both crated and uncrated) due to Stem-end Rot.

On these points the definite recommendations submitted should contribute materially to the welfare of the Industry.

We have the honour to be,

Gentlemen,

Yours respectfully,

CLALDE W. WARDLAW, Pathologist.

LAURENCE l'. MCGUIRE, Physinlogist. 



\section{THE BEHAVIOUR AND DISEASES OF THE BANANA IN STORAGE AND TRANSPORT.}

\section{INTRODUCTION.}

THE Low Temperature Station was erected for the study of the 1 cold storage and transport of the banana; of late years the prevalence of Panama Disease, to which the Gros Michel banana, the chief variety of commerce, is susceptible, has necessitated a concerted attack on the problem from the genetical, pathological and physiological standpoints.

Our attack then involves plant breeding experiments with a view to the production of an immune or highly resistant hybrid of desirable bunch characteristics ; secondly, the detailed study of the pathogenic organism, its mode of infection and spread, etc., with a view to curative or preventive measures: and, thirdly, the selection of the most suitable of the existing varieties of proved immunity or high resistance, and the determination of the precise set of conditions suitable to its successful transport overseas and subsequent ripening to an attractive yellow colour. The following is an account of research work carried out by the Pathologist and the Physiologist in collaboration.

From the point of view of cold storage, the banana is perhaps unique among the fruits which have claimed the serious attention of the refrigeration biologist. Most fruits are confined to a short season annually. Such fruits are picked comparatively mature, and when they are held under suitable conditions, senescence and decline may be delayed for varying periods, according to the variety in question, thus serving economic ends. The banana, however, fruits all the year round, and thus the question of storing the fruit so as to aroid the low prices of the "glut" does not arise. Furthermore, in sharp contrast with other fruits, the banana is harvested quite green ; after a short period, during transport at temperatures in the neighbourhood of $53^{\circ} \mathrm{F}$, it is ripened up in a few days at a higher temperature (about $70 \mathrm{~F}$.) and placed on the market. In dealing, therefore, with a 
proposed substitute for the Gros Michel variety, our problem is the determination of the correct stage of maturity at harvesting, and the precise conditions during transport and subsequent ripening which will ensure that the product for market is a neat and orderly bunch of attractive colour.

\section{Acknowledgments.}

In submitting this report, we wish to express our sincere thanks to those who have assisted us in this work. The Principal, Mr. G. Evans, II.A., C.I.E., has not only shown an encouraging interest in all matters relevant to Banana Research and the Low Temperature Station generally from the outset, but has assisted very materially, in conjunction with Mr. E. E. Cheesman, Professor of Botany, and Captain R. C. Marshall, Conservator of Forests, Trinidad, to whom we also extend our thanks, in securing supplies of fruit for storage experiments, by planting up areas of Government Forest Reserve at Arena. In our mycological investigations, where facilities for work were kindly provided in the Department of Professor H. R. Briton-Jones, we are deeply indebted to Mr. S. F. Ashby, for verifications and identifications of organisms isolated, and here we wish to express our appreciation of the exceedingly useful services rendered by the Imperial Bureau of Mycology, which we feel sure is shared by all biologists in the Colonies. We should also like to place on record the pleasure we have had from the informal co-operation between the Low Temperature Station, Cambridge, and ourselves, and the usefulness of the exchange of information from time to time. In extending our studies to large scale consignments, we have been greatly assisted by Messrs. Elders \& Fyffes, who, with extreme courtesy, have given us every facility and freedom for examining cargoes at Port of Spain, a privilege which was rendered still more pleasing by the kindly and helpful reception invariably extended to us by the Captain and officers of the ships visited. Finally, we have to thank Mr. E. J. Wortley, O.B.E., Director of Agriculture, Trinidad, for permission to bring ashore such material as we required for our investigation of Main Stalk Rot.

\section{PRELIMINARY STORAGE TRIALS.}

The material for earlier storage trials was obtained from the College plots at Arena, where a considerable acreage has been planted under bananas of the following varieties :- Gros Nichel, Cavendish, Congo, Lacatan, Bumulan, Giant Fig, and the hybrid G MI $\times$ B2. 
The supply was supplemented further from the College Farm in st. Augustine. Illustrations of the more important varieties are shown in Figs. 1 to 6.

In commencing the earlier storage trials, it was realised that it would be difficult indeed to obtain sufficient fruit of any one particular
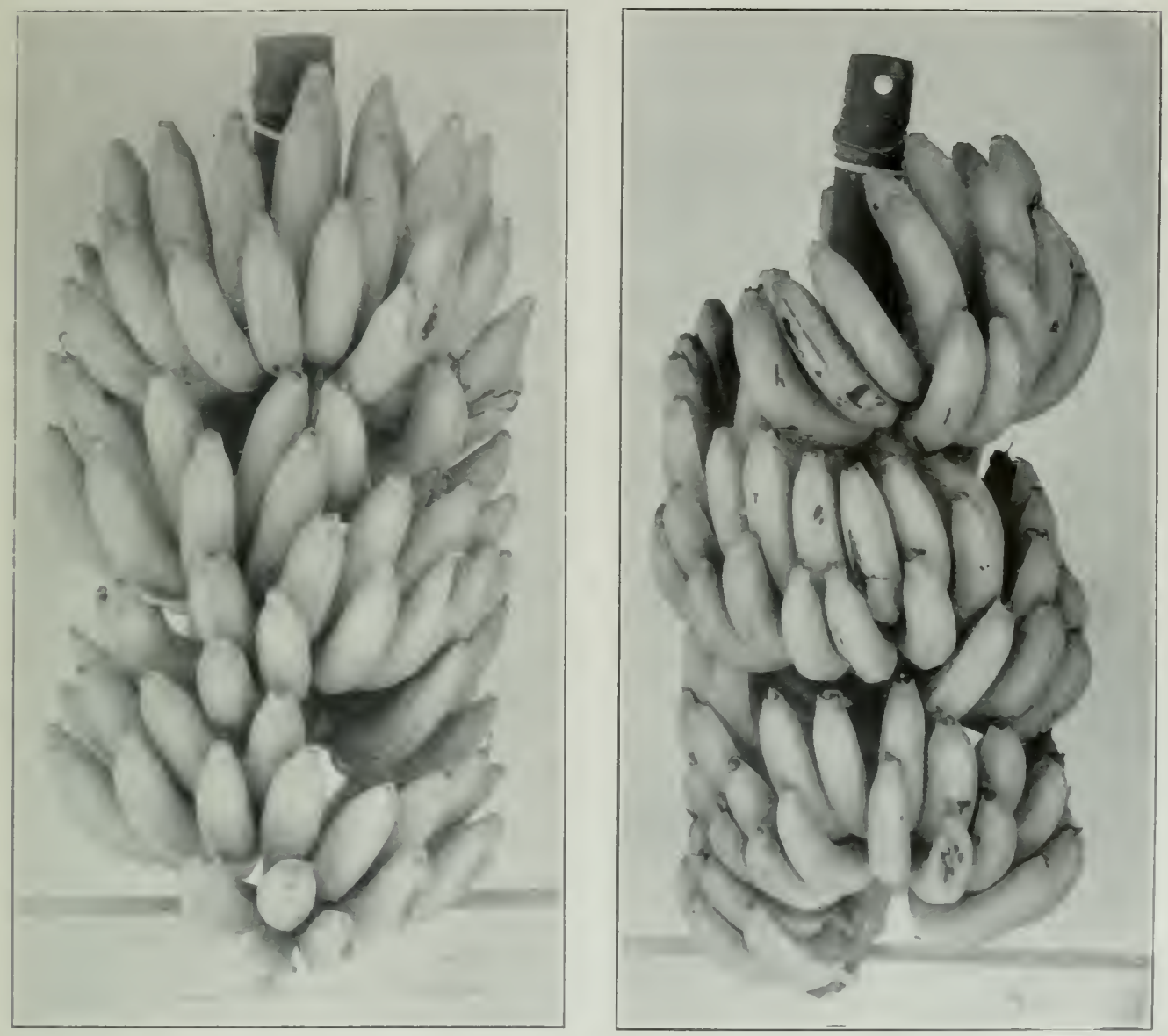

Fig. 1.-.-1 Giros Michel bunch. Notesymmetry.

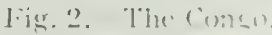

variety to fill a storage chamber to a capacity approximating to normal ships' conditions ; it was, therefore, decided to use all available bunches of suitable maturity. The failure of small trial shipments of prssible substitutes, carried in the holds with the Gros Vichel, is 
popularly believed to be due to something akin to contamination by the Gros Michel. We preferred rather to attribute this failure to the fact that the conditions farourable for the successful transport of the

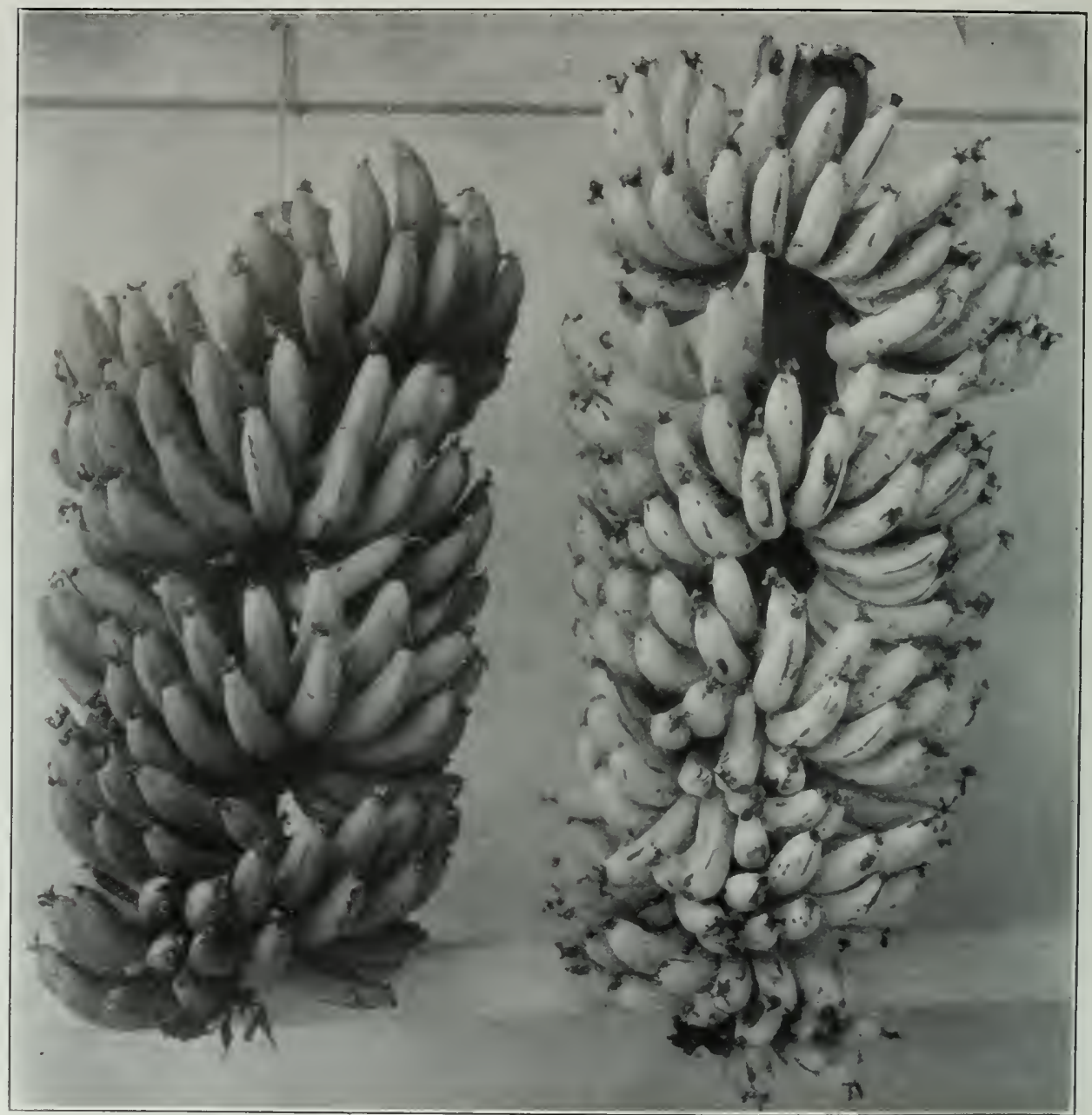

Fig. 3.- The Cavendish variety-good Trinidad fruit. Left, green; right, advancing maturity.

Gros Michel were unsuitable to the requirements of other varieties (cf. the successful long storage of some apple varieties at $32^{\circ}-33^{\circ} \mathrm{F}$., while these temperatures have been shown by various workers to be 
responsible for the onset of premature physiological breakdown in others). Until, therefore, definite inter-varietal contamination presented itself, and until the range of temperature and humidity favourable to a variety could be reduced to narrower limits, there
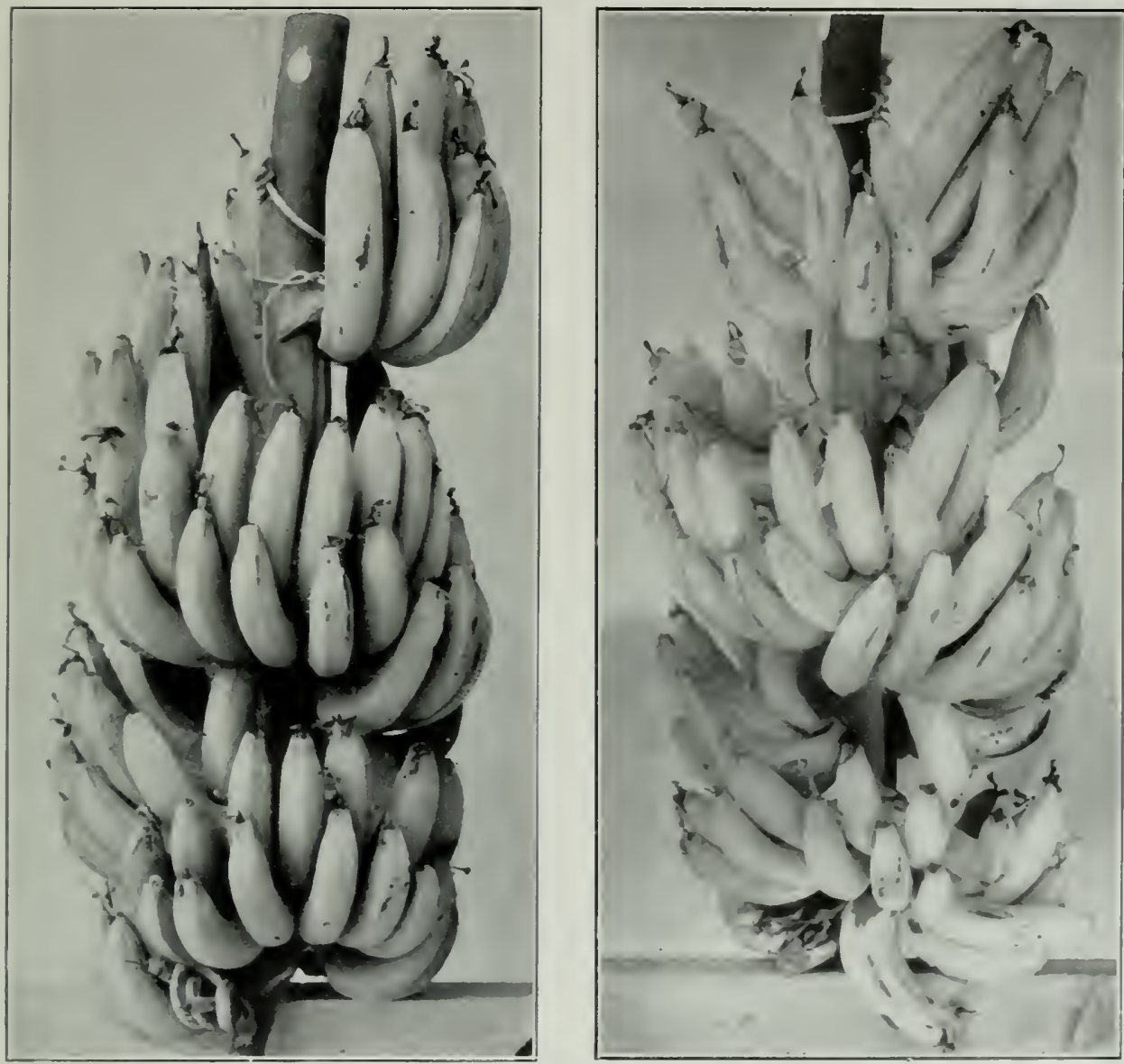

Fig. 4.-The Lacatan. Left, green; right, same bunch during ripening. Note departure from original symmetry and premature ripening in bottom hand due to break in stem.

seemed no objection to storing several varieties together, yuite apart from the valuable data arising from a comparison of the storage behaviour of these varieties under precisely similar sets of conditions. 


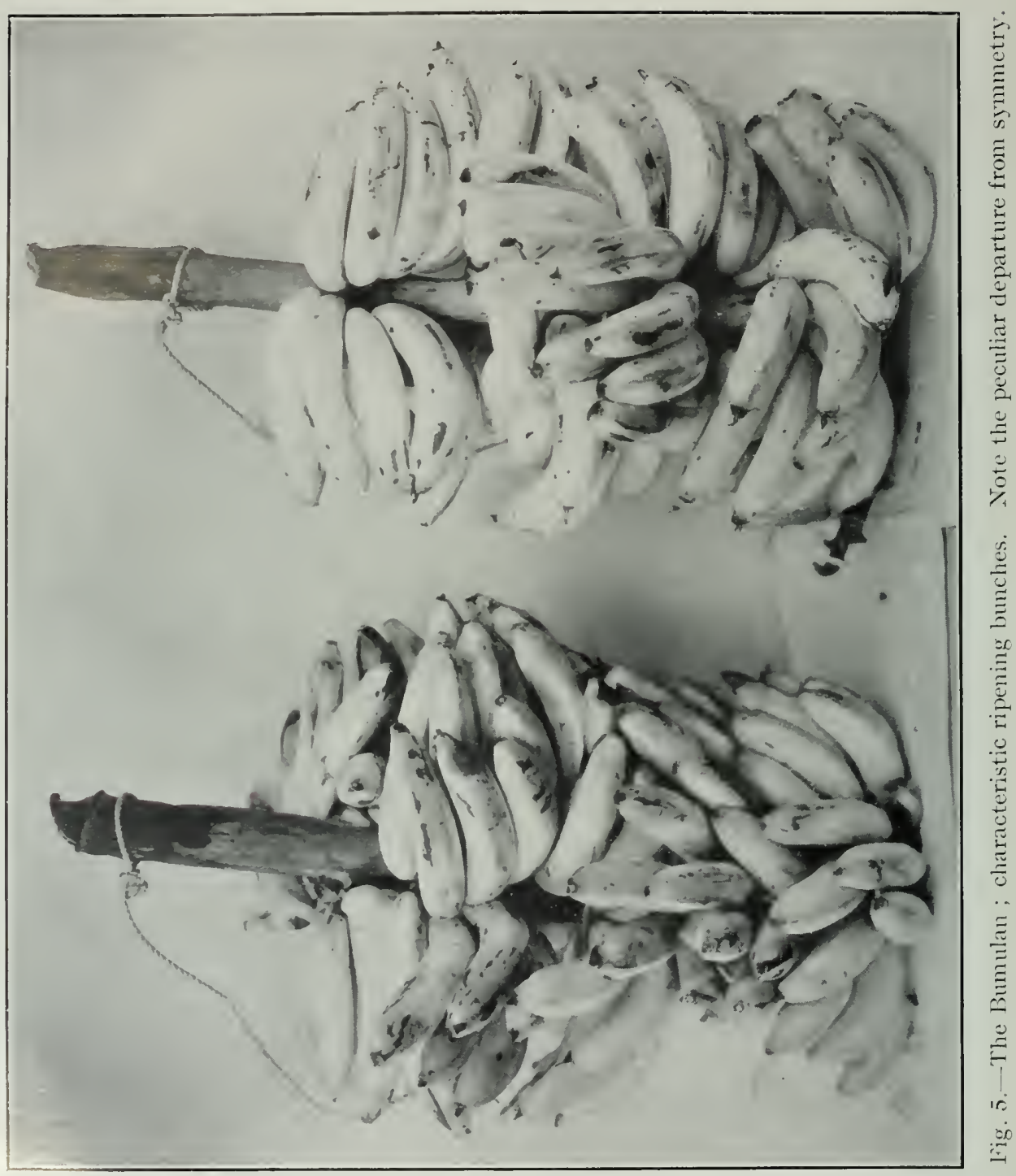


In selecting material for experimental storage, a careful and minute inspection of each individual fruit is necessary, so that fruit which is bruised or damaged in any way may be rejected. In the case of a "bunched" fruit of the habit of the banana, however, where successive whorls or hands fold back towards the central axis, this

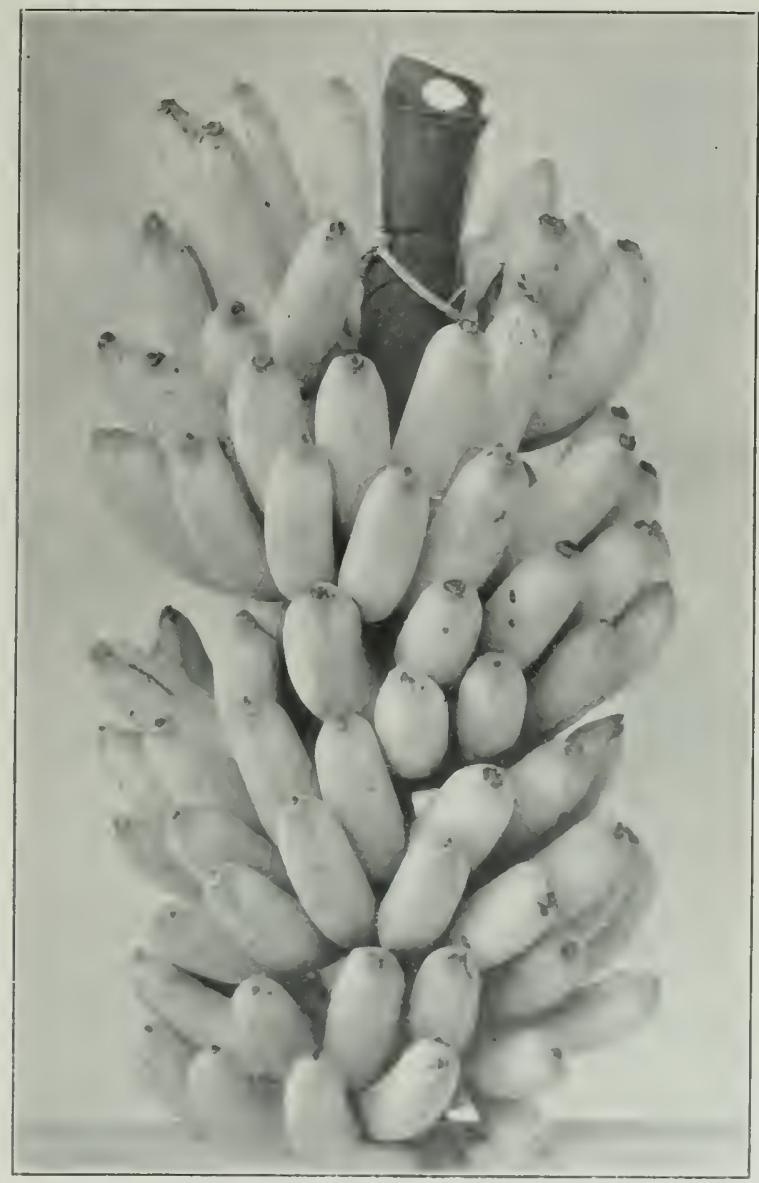

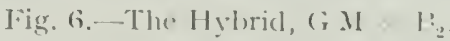

procedure is untenable. Further, no matter how carefully transport is arranged, a certain percentage of bunches are invarialily bruised to a greater or less extent, quite apart from scratches, etc. from insects and animal life which make their aborke there. In the earlier 
trials, therefore, instead of a wholesale rejection of bunches, all perceptible individual injuries-mutilations, bruises, broken stalks, damaged hands and fingers, etc.-were labelled, and further developments noted in the course of inspection at regular intervals. In addition, several deliberate punctures were made and certain fingers were twisted, these being labelled too. In due course the labelling was dispensed with, as it soon became evident that the behaviour of bruises, mutilations, etc., was standardised-there was a tendency to darken in colour during the storage at the cool temperature, which later, on transference to the ripening room at higher temperatures, dereloped into blackened patches, with the establishment of Gloeosporim and other fungi. In the case of fingers twisted and damaged at the stem, the progress of infection in the advanced stages was accompanied by finger dropping.

While our attention was drawn to the alarming wastage in banana cargoes, due to main-stalk rot, the amount found in our chambers was practically negligible, due chiefly to the rapidity with which our small consignments were cooled down. It was realised that with bulk storage later, the problem would become more acute. The effect of cutting the stems with a hot sharp knife, making a clean cut, and smearing with ordinary laboratory vaseline, gave good results from the start. Later experimental work showed that it was not necessary to heat the knife. Various antiseptic solutions, melted fats, tallows, etc., were not tried, as it was felt that this simple smearing operation which was quite efficacious, would be far more practicable in large scale operations.* Fig. No. 7 shows clearly the beneficial effect of making a clean cut and applying a smear of vaseline. This will be referred to later.

Finger-dropping, another source of wastage, may be due to:-

(1) Advanced stage of main stalk rot, where infection has passed through the cushion into the individual finger stalks.

(2) Mechanical injury to individual fingers, which become associated with Gloeosporimm and other fungi.

* While the vaseline treatment of stems has been a portion of ordinary laboratory procedure from our earliest storage trials, priority in this matter goes to Dr. Tomkins, of the Low Temperature Station, Cambridge, in whose name, we learn from London correspondence of 11 th April, 1930, a patent has been granted. We wish to record our pleasure in confirming this treatment, though we draw attention to our later remarks on its applicability to large scale operations, and stress the futility of applying even in generous quantities, to stems either badly cut or bruised below the also Jour. Soc. Chemical Industry, Vol. XLIX, No. 26, 1930. Tomkins, R. G., dman, R. M.) 


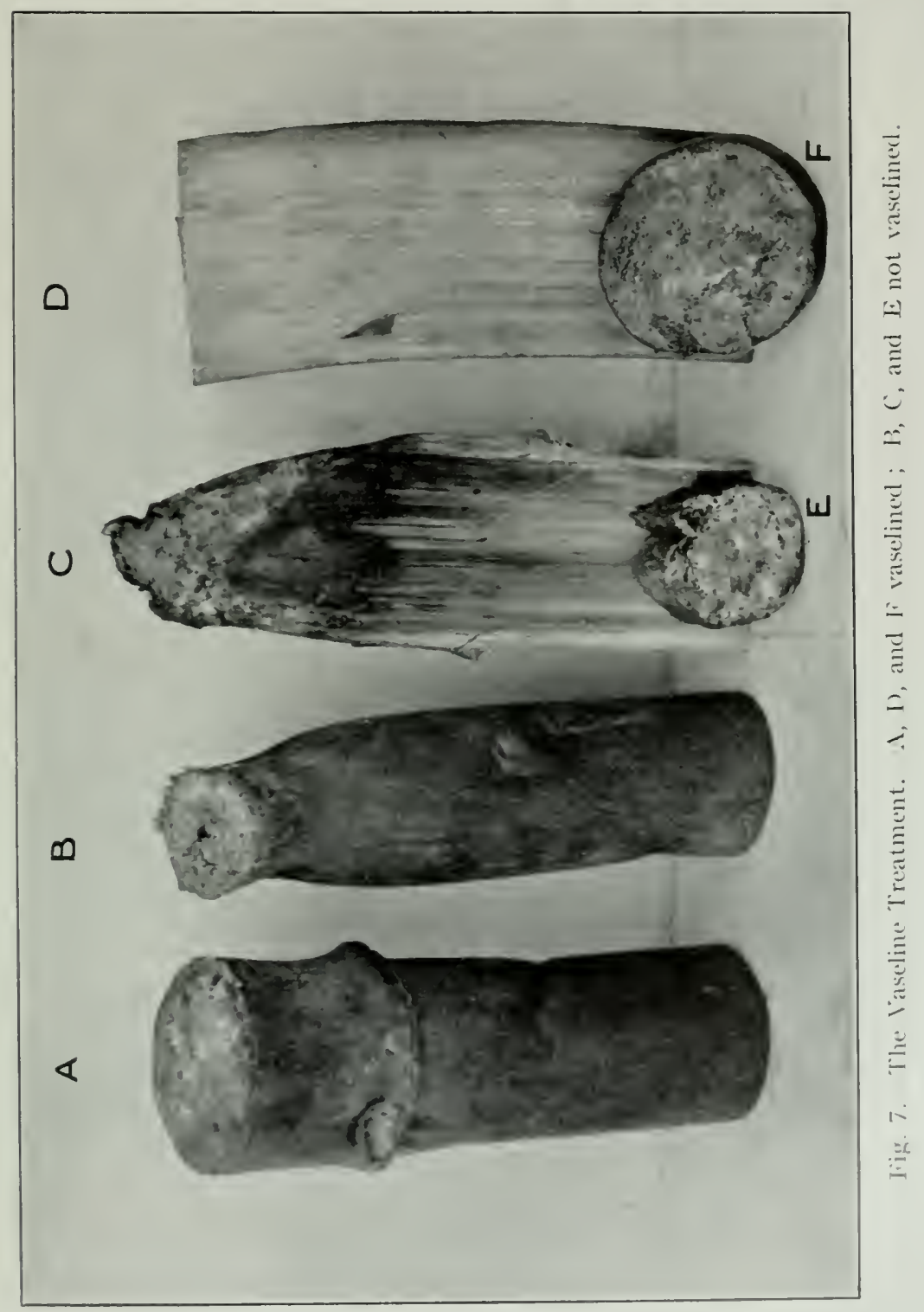


(3) Late maturity. Figs. 8 and 9 illustrate typical fingerdropping as a result of reaching the over-ripe stage.

In these earlier trials, the Gros Michel was used as a standard of comparison, and the behaviour was studied of the varieties mentioned
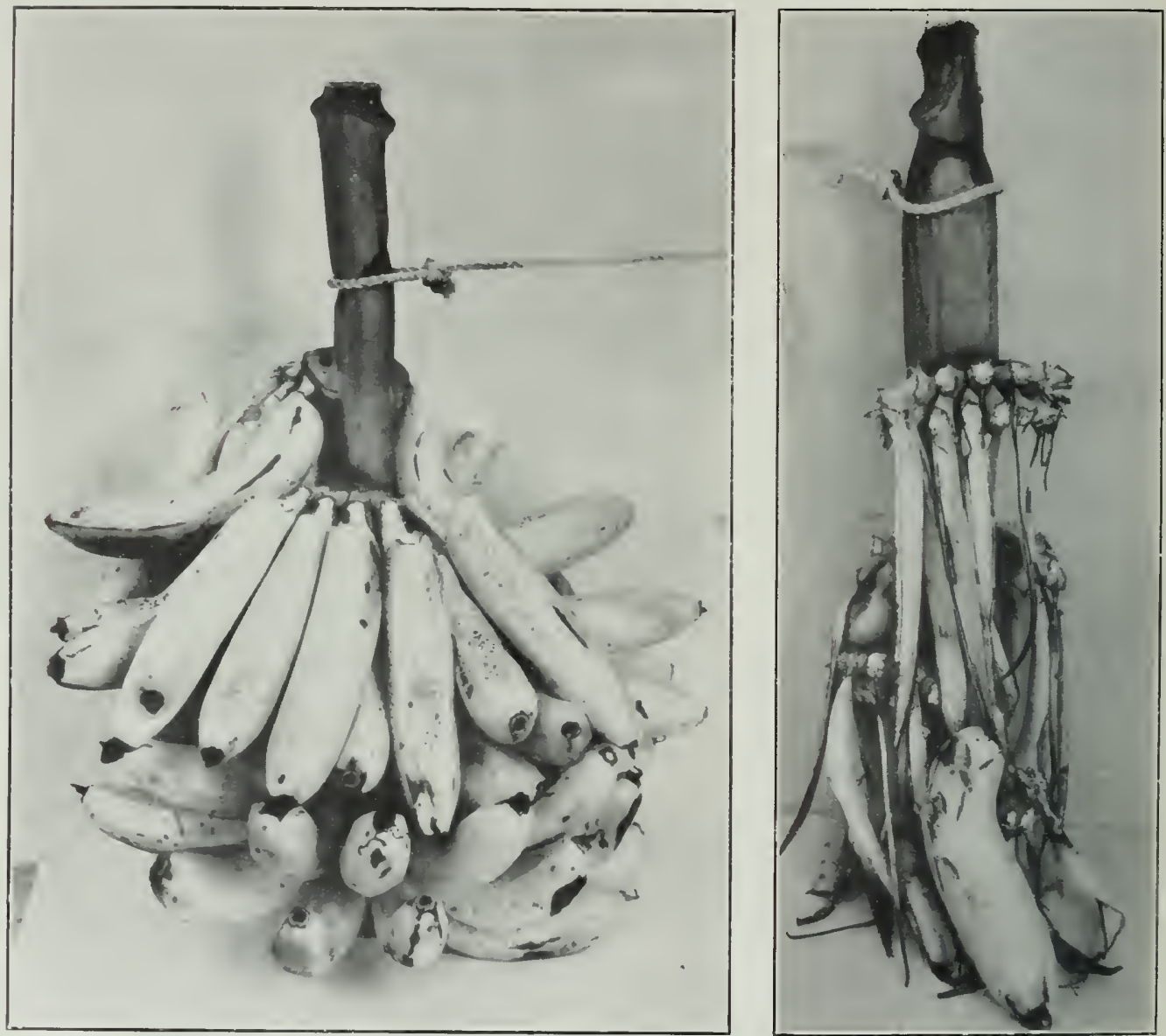

Figs. 8 and 9.--Stages in Finger-dropping due to late maturity in the Gros Michel.

above, when kept for varving periods of 14-17 davs at fixed temperatures ranging between $53^{\circ} \mathrm{F} .60 \mathrm{~F}$. with humidities between 65 and 90 per cent., after which they were ripened up at $70^{\circ} \mathrm{F}$. 
Full descriptions of these varieties appear elsewhere in print, so repetition will be avoided here. A summary of characteristics evident after cool storage for 14 days and subsequent ripening, is tabulated below.

\section{TABLE I.}

Observation on.

Ippearance of bunch

Colour when ripe .. Excellent, deep rel-

Texture a . . Evenness of ripening

1)isprosition of fingers

Preclisposition to mechanical injury and bruising.

Speed of ripening of "I-full" bunch at 7) $\mathrm{F}$ a after 14 davs cool storage. l'erfectly simmetrical: fingers 1 p)right and converging back to central axis, low luse.

\section{show badly.} Excellent and high sHCTOSE.

Symmetrical when green; loses svmmetry when ripening: fingers tend to spread towards the horizontal.

Occasionally excellent, but frequently a poor. pasty colour ; bruise's

Delicalte

Standarel ..

Highly uniform

linger stem sufficiently fibred to hold fingers until reaching over-ripe stage.

Comparatively thick skinned, allowing of fairly rough handling.

+ fi days ligorous bunches ripen evenly, but majority unevenly:*

Often departs from erece position with maturity : finger stalks secm deficient in fibre.

Verv thin skin: all bruises show badly even at early stages.

Very uncertain ; vigorous bunches 5 -s days. but usually $11-14$ lays.*
The usual objection on account of outward curvature of the fingers not fully justified (see bulk storage trials).

Excellent, but pale, and tendency to freckling with adrancing maturity.

Better than Gros Michel, but not so sweet as bacalian.

belicate.

Higlıly uniform.

linger stem sufficiently fibrexl.

Very susceptible to injury.

4 fidals.

* May be due to nutritional facturs soil and clinate.

\section{TABLE II.}

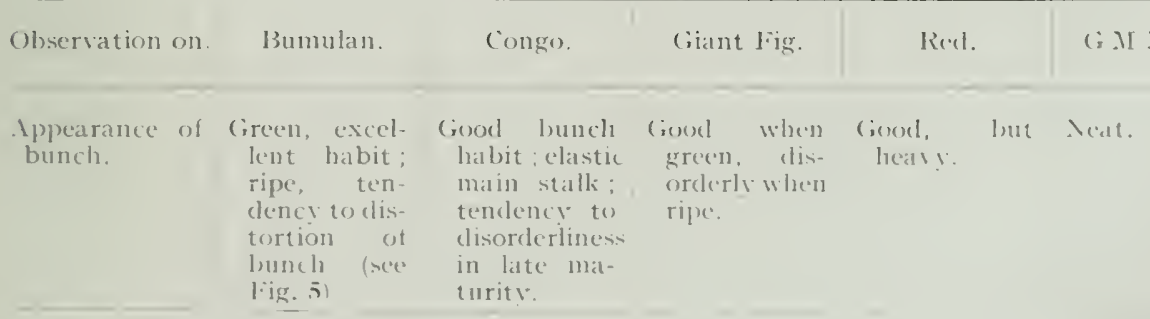


Observation on. Bumulan.

Congo.

Giant Fig.

Red.

$\mathrm{G} M \mathrm{X} \mathrm{B} \mathrm{B}_{2}$.

\begin{tabular}{|c|c|c|c|c|c|c|}
\hline $\begin{array}{l}\text { Colour when } \\
\text { ripe. }\end{array}$ & Good & Very good & $\cdots$ & $\begin{array}{l}\text { Pasty green- } \\
\text { ish yellow } \\
\text { (sometimes } \\
\text { good colour- } \\
\text { ing). }\end{array}$ & $\begin{array}{l}\text { At tractive } \\
\text { claret colour. }\end{array}$ & $\begin{array}{l}\text { Excellent, re- } \\
\text { calling Gros } \\
\text { Michel. }\end{array}$ \\
\hline Texture & Coarse $\quad$. & Moderate & . & $\begin{array}{l}\text { Moderately } \\
\text { good. }\end{array}$ & Coarse & $\begin{array}{l}\text { Pleasing, but } \\
\text { probably an } \\
\text { a c } " \text { i } \mathrm{re} \mathrm{d} \\
\text { taste. } \\
\text { Very delicate. }\end{array}$ \\
\hline $\begin{array}{l}\text { Evenness of } \\
\text { ripening. }\end{array}$ & $\begin{array}{l}\text { Moderately } \\
\text { uniform. }\end{array}$ & Uniform & . & Very uneven* & $\begin{array}{l}\text { Highly uni- } \\
\text { form. }\end{array}$ & $\begin{array}{l}\text { Highly uni- } \\
\text { form. }\end{array}$ \\
\hline $\begin{array}{l}\text { Disposition of } \\
\text { fingers. }\end{array}$ & $\begin{array}{l}\text { Fingers sag } \\
\text { when ripen- } \\
\text { ing, giving } \\
\text { disorderly- } \\
\text { appearance. }\end{array}$ & $\begin{array}{l}\text { Tendency } \\
\text { sag. }\end{array}$ & to & $\begin{array}{l}\text { Marked tend- } \\
\text { ency to sag. }\end{array}$ & $\begin{array}{l}\text { Finger stem } \\
\text { sufficiently } \\
\text { fibred to } \\
\text { hold fingers } \\
\text { erect. }\end{array}$ & $\begin{array}{l}\text { Fingers re- } \\
\text { main erect } \\
\text { until ad- } \\
\text { vanced ma- } \\
\text { turity. }\end{array}$ \\
\hline $\begin{array}{l}\text { Predisposition } \\
\text { to mechanical } \\
\text { injury and } \\
\text { bruising. }\end{array}$ & Slight $\quad$. & Slight & . & Marked & Very slight . . & Very slight. \\
\hline $\begin{array}{l}\text { Speed of ripen- } \\
\text { ing of " } 3-f u l l " \\
\text { bunchat } 70 \mathrm{~F} \text {. } \\
\text { after } 14 \text { days } \\
\text { cool storage. }\end{array}$ & $\begin{array}{l}\text { Variable, 8-13 } \\
\text { days. }\end{array}$ & f-9 day's & . & $10-14$ daỵs. & last, 4 6 days & Fast, 4-6 days \\
\hline
\end{tabular}

* May be due to nutritional factors - soil and climate.

The following conclusions could be drawn from the earlier storage trials of uncrated fruit :-

(1) From a consideration of bunch habit, attractiveness on ripening, flavour, etc., the varieties could be divided into two main groups :--

(i) Gros Michel, Lacatan,* Cavendish--varieties of definite commercial possibility ; and

(ii) Those of doubtful commercial possibility. It should be noted that $(\mathrm{I})$ the GM $\times \mathrm{B} 2$ has a good flavour and texture and many desirable Gros Michel characteristics, but the unfortunate possibility of an occasional seed precludes its inclusion in the first group; and (II) the Red banana behaves well in storage at both $55^{\circ} \mathrm{F}$. and $60^{\circ} \mathrm{F}$., and has been exported quite successfully. There is, however, not a large market for it, its chief attraction in competition with other varieties on the market being its rare claret-red colour.

* Attention was drawn to the importance of this variety in our report, E.M.B. 20. 22 
(2) There seems to be a correlation between pre-storage nutritional factors of soil and climate, and the behaviour in storage and ripening. Our bananas are grown on patchy soils, and while, for the most part, we have not been consistently successful in the ripening up of several varieties, we have noticed that occasional vigorous bunches have ripened very attractively. This was particularly noticeable in the case of the Lacatan which had been kept at $60^{\circ} \mathrm{F}$. during the cool storage period.

(3) The excessive tenderness and susceptibility to bruising usually associated with the Cavendish, i.e., necessity for crating, were not borne out by these trials; careful handling obviated the major objection, namely, the breaking off of the fingers, which tend to curl upwards and rather outwards.

(4) The majority of irregular colouring up of fingers and the premature ripening of lower hands, were found to be due to fungal attack as a result of insect punctures or mechanical damage during harvesting and transport.

\section{BLLK STORAGE TRIALS.}

As pointed out above, our earlier trials led us to regard the Lacatan and the Cavendish as possible substitutes for the Gros Nichel. The Lacatan was left over for the time being, as, until the newer extension plots come into bearing, the behaviour of this variety in bulk storage could not be undertaken. The Carendish, on the other hand, is largely grown by Indian peasant proprietors throughout the island, and is widely distributed through the Windward and Leeward Islands. It is a dwarf plant, and is, therefore, more suitable to wind-swept sites. The importance of such work to the islands of the British West Indies, where, owing to the prevalence of hurricanes, a suitable annual crop is urgently needed to supplement a languishing staple crop, needs no further comment here.

Accordingly, bulk storage trials with the Cavendish variety were commenced, and up to the present we have conducted four.

The material was obtained towards the end of the dry season when fruit is very scarce, and was, therefore, not of the uniformity of good plantation fruit. It was purchased from numerous individual proprietors. In the ordinary way, a good deal of it would have been rejected, but was accepted in order that the complex of bulk, with consequent self-heating of fruit, might be introduced into our storage trials. 


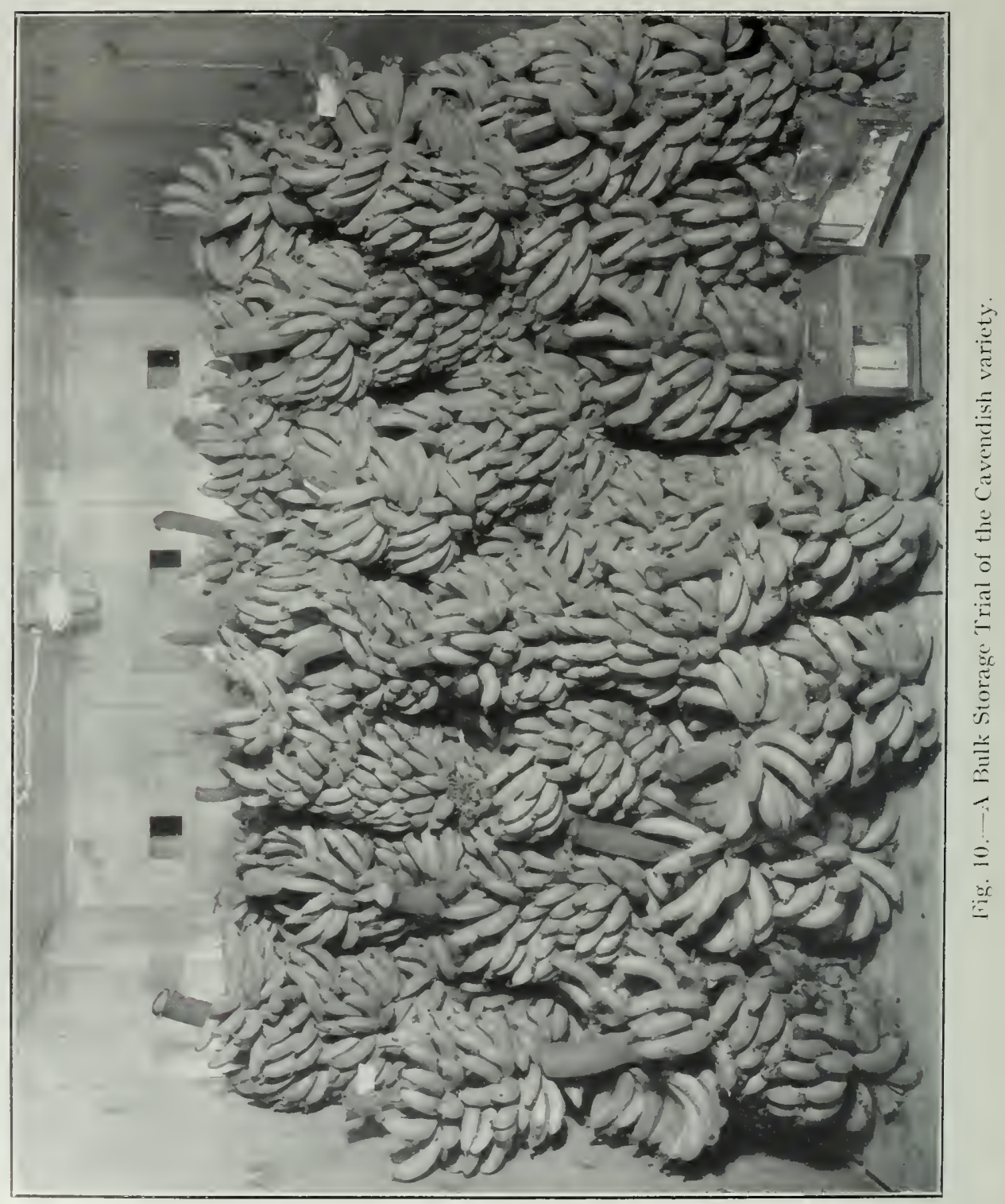


Care was taken to lessen as much as possible the interval between the reaping of the consignment and the commencement of refrigeration. On arrival at the Station, the bunches were conveyed into the air lock,* examined, and the stems cut and raselined; after this they were, as shown in Fig. 10, loaded into the storage chamber (air temperature $53^{\circ} \mathrm{F}$.). This is the way in which the Gros Michel is handled in bulk, and it will be seen that the layer of bunches on the floor is subjected to the weight of several tiers of fruit above it. The concentration of carbon dioxide was determined at frequent and regular intervals; during the "voyage" period at the lower temperatures it was found normally to range between 0.05 per cent. and 0.22 per cent., and in the ripening room at higher temperature, between $0 \cdot 0 \bar{s}$ per cent. and $0 \cdot 3 \bar{j}$ per cent. This has been slightly exceeded on one or two occasions at the end of a storage trial when fruit which had reached the over-mature stage had not been removed. In consequence of these small concentrations it was found necessary to change the storage atmosphere completely only once daily $(6 \mathrm{p} . \mathrm{m}$.) and not twice as is the routine procedure of ships carrying banana cargoes.

By way of simplifying the description of results, the details of the four bulk storage trials are tabulated below :-

\section{TABLE III}

\section{Observations.}

(1) Number of bunches used

(2) Temperature of store after fruit lias been conled down.

(3) Humidity of storage chamber

(4) Time before air temperature was $5.3 \mathrm{I}$.

(a) Delivery

(b) Return

(5) Number of days in cool storage .

(6) Number of "ship-ripes"

(7) Number of total rejects . .

(s) Temperature of ripening rom . .

(9) Number of at tractive ripes in six days . .

(10) Further attractive ripes by the tenth day

(11) Number which failed to ripen
Bulk Trial.

No. 1.

120

$53 \mathrm{~F}$; for the

last six days.

$52 \cdot 5 \mathrm{~F}$.

$80-20,0$

23 hours.

45 lours.

17

2

Nil

$701:$

(3)

48
Bulk Trial.

No. 2.

$230^{\circ}$

$52 \cdot 5 \mathrm{~F}$

$8.590 \%$

12 liours.

19 licurs.

$18 !$

$\mathrm{NiT}$

1 (broking stallk).

7) 1 .

137

(i2)

Nil

* While the une of an air lexe is net practicable in large scale shipments, it lass, nevertheless, materially assisted us in the rapiol oushing of our fotit. Ender these conditions, onr comsignments bave remained comparatively free from main-stalk rot, while the Trade's ol,jeetion, namely, risk of chilling, wats nut experiencert.

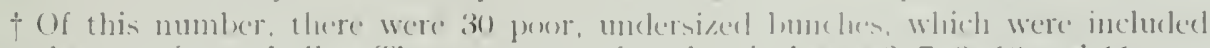
merely to make mp bulk. These are net referred to in ltems 6, 7, 9, 111 and 11. 


\section{TABLE IV.}

\section{Obseriations.}

(1) Number of bunches used .

(2) Temperature of store after fruit has been cooled down.

(3) Humidity of storage chamber

(4) Time before air temperature-

(a) Delivery

(b) Return was $\overline{5} 3^{\circ} \mathrm{F}$...

(5) Number of days in cold storage

(6) Number of "ship-ripes" ..

(7) Number of total rejects ..

(8) Temperature of ripening room

(9) Number of attractive " ripes "in six dars

(10) Further attractive " ripes " by the tenth day's.

(11) Number which failed to ripen
Bulk Trial.

No. 3.

$136^{*}$

$52^{\circ} \mathrm{F}$.

$80-90^{\circ}{ }_{0}$

$10 \frac{1}{2}$ hours.

$15 \frac{1}{2}$ his.

21

1

1 (damaged stem).

$70^{\circ} \mathrm{F}$.

67

55

Nil.
Bulk Trial.

No. 4.

124

$52^{\circ} \mathrm{F}$.

$80-90^{\circ} \%$

$7 \frac{1}{2}$ hours.

$14 \frac{1}{2}$ hrs.

22

5

1 (over-ripe).

$70^{\circ} \mathrm{F}$.

113

5

Nil.

There is, therefore, a wide range of maturity under the trade term " 3 -full," at which the Cavendish banana may be picked, so that it will stand uncrated the usual bulk store conditions at $52 \cdot 5^{\circ} \mathrm{F}$. for as long as 18.1 days. While on being ripened it has not the rich hue of the Gros Michel, the better and more vigorous bunches were extraordinarily symmetrical and attractive (see Figs. 3 and 11), especially before the onset of freckling, concomitant with late maturity in this variety. Even bunches which were thought to be too immature ripened up to a produce of pleasing flavour and appearance in 13 days. This would, of course, increase ripening costs.

If these results are confirmed in later storage trials, a hopeful note may be sounded regarding the possibilities of the West Indian Cavendish, as exemplified by the better-grade Trinidad fruit (see Frontispiece and Fig. 3), as a substitute for the Gros Michel.

* Of this number, 12 were very poor bunches of small count as a result of the long protracted drought and are, therefore, not included in items $6,7,9,10$ and 11.

† While these were rather more than " $\frac{3}{4}$-full" at time of harvesting, they had not ripened to an extent which would make trade-handling impracticable.

‡ During the bulk storage trials it became obvious, especially on ripening, that the Cavendish, as exemplified by Trinidad fruit collected casually, shows great variation. Whether this is due to nutritional factors or the existence of several genetic strains, remains to be decided. It has been suggested by Mr. G. Evans that definite information on this matter would be a useful corollary to the storage work already undertaken. 26 


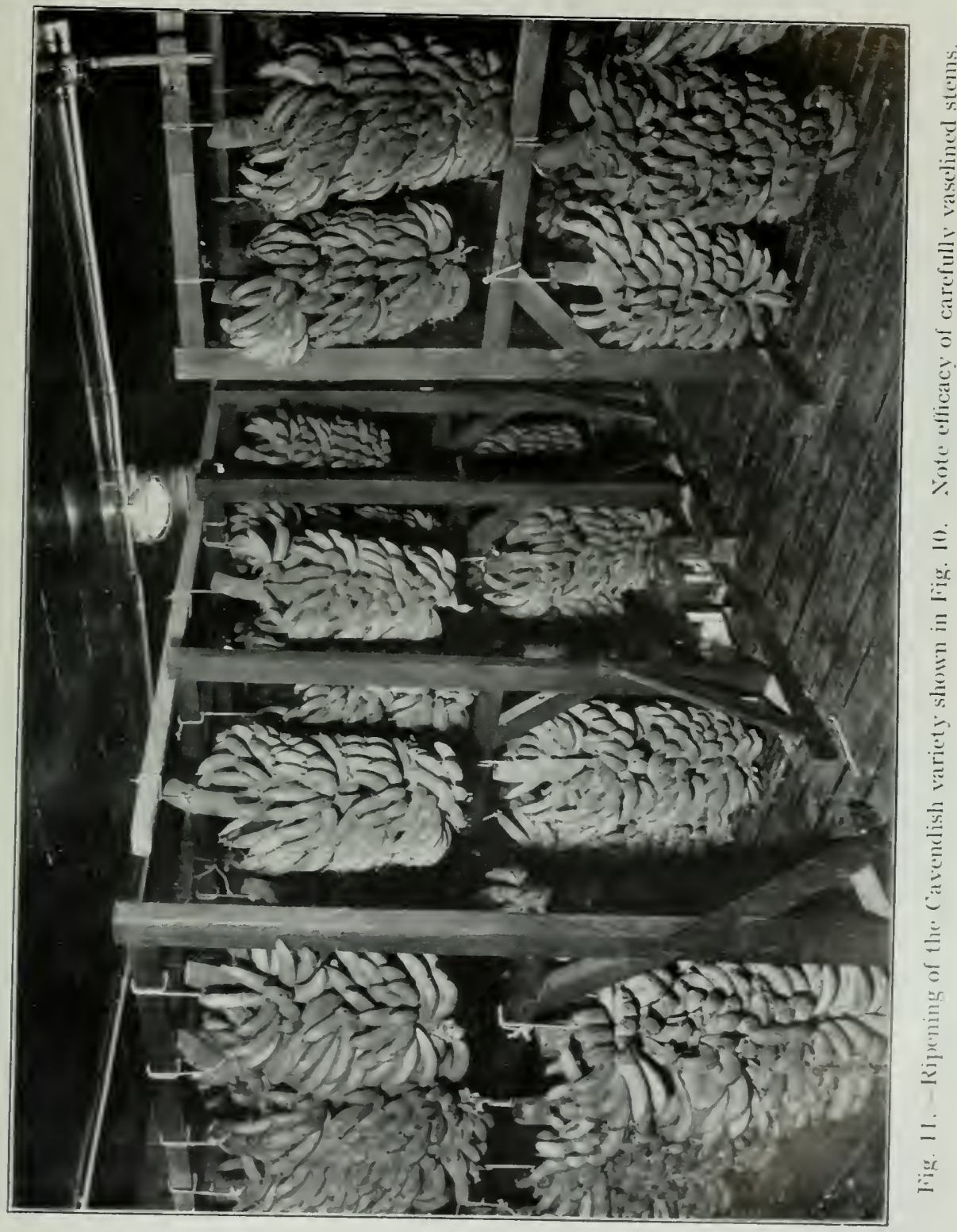


While the amount of main-stalk rot in the second trial was in no way commensurate with the incidence and spread reported by shipping authorities, there was, however, sufficient to convince one that the raseline treatment is by no means fool-proof, especially in
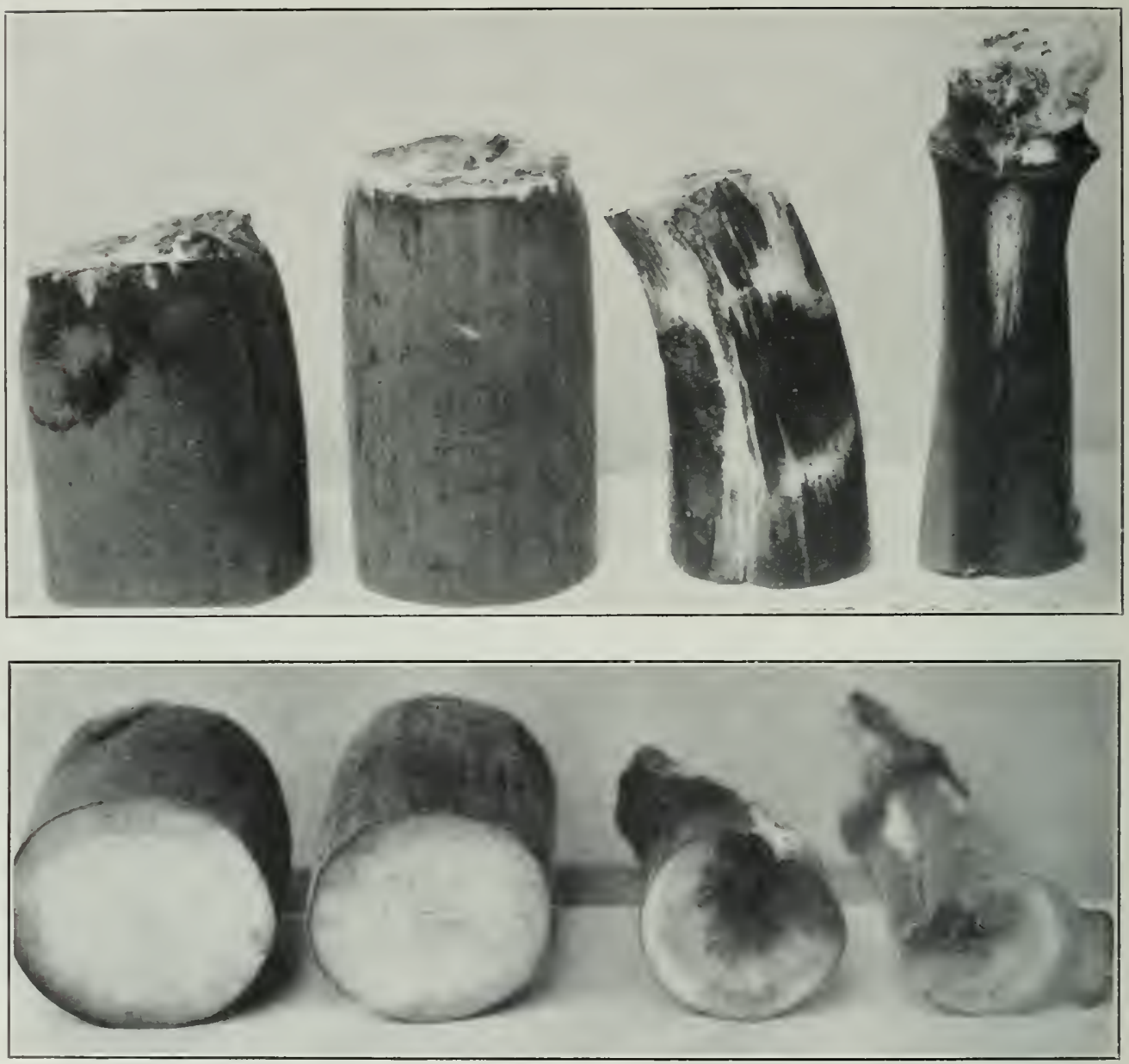

Fig. 12.-A comparison of carefull $y$ and carelessly vaselined stems after bulk storage $\left(18 \frac{1}{2}\right.$ day's at $\left.52 \cdot 5 \mathrm{~F}\right)$.

the hands of Trest Indian labour. Fig. 12, illustrating representative stem raseline, even in generous quantities, to stalks cut clumsily or bruised $2 S$ 
in any way below the cut. Care in handling, with a riew to obviating damage to main stalks, is an important adjunct to the treatment above described.

\section{OBSERVATIONS ON FUNGI AT THE LOW TEMPERATLRE STATION.}

I. Introduction.

During the course of storage trials, the activity of various fungi became evident, fruit, finger-stalks, and main-stailss being affected to a greater or less extent. Following the usual mycological procedure, fungi were isolated by planting small pieces of diseased tissue on various culture media. The collection of organisms isolated included Thielariopsis paradoxa (De Seyres) Ton Hohn., (Ceratostomella paradoxa Dade). Glocosporium musarum, Cke. and Massee, Botryodiplodia theobromae Pat., Phomopsis sp., Nigrospora sp. Eidemia sp., lerticillium sp., several species of Fusarium, and other fungi not ret identified.

The investigations to be reported on here do not claim to represent in detail either the physiology or the parasitic behaviour of these organisms. The experimental work so far carried out has been to determine their general behaviour when brought into contact with the banana under commercial storage conditions.

Two aspects have been considered :-

(1) The rate of growth of the organisms at different temperatures.

(2) Their parasitic behaviour as determined by inoculation experiments.

At this point a word may be said on the subject of terminology. Disease of fruit in transport has been collectively described as Stemend Rot. This term leads to confusion, as different diseases are implied by different workers. Thus, the Stem-end Rot described by simmonds, * refers to a rot of the short fruit stem, i.e., where the finger joins the main stem. On the other hand, we understand that the disease of the same name on fruit transported for the English Market refers to a clownward rotting of the main-stalk of the whole bunch. We therefore propose to adopt the following terminology : The individual banana fruit may conveniently be described as a

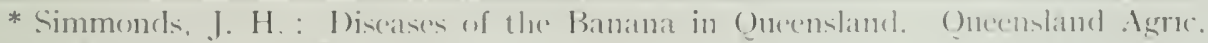
Jomr., XYX No. . 1928. 
"finger," and its short stalk as the "finger-stalk" ; where several " finger stalks " meet to form a "hand," a cresentic "cushion" is formed. These "cushions" project from the "main-stalk" of the whole bunch. At the Low Temperature Station the sereral aspects of disease to which attention has been given may be described as follows :

(1) Main-stalk Rot, i.e., a downward rotting from the cut end of the main stalk. This is the disease popularly described as Stem-end Rot, which causes trouble when fruit is remored from the holds at English ports. (Thielaviopsis, Botryodiplodia, Glocosporium.)

(2) Local Lesions of Main-stalks.-Infections may become established at points along the main-stalk. Localised or spreading blemishes or cracks may result. (Thielaviopsis, Gloeosporium, Phomopsis.)

(3) Cushion Infections. - Isolated infections frequently become established on the cushions. According to the fungus involved, a limited blemishing or an extensive rotting, extending to fingerstalks and fingers, may result. (Gloeosporium.)

(4) Finger-stalk Rot.-This type of localised infection on indiridual finger stalks is fairly frequent, and may be the cause, or a contributory cause, of finger-dropping. (Gloeosporium.)

(5) Finger Diseases may become established at the distal end or at other points on the fruit skin. They sometimes result from a spread of finger stalk rot to the fingers. (Glocosporium.)

\section{Literature on Banana Fruit Diseases.}

Our information on Banana Fruit Diseases is relatively inextensive. A number of parasitic organisms have been described, some of which have a wide geographical range. Significant parasitism may take place in the field, or disease may only make its appearance on fruit during storage or transport. The parasitic organisms which have been reported in relation to main-stalk, finger-stalk, and fruit diseases, include :

(1) Gloeosporium musarum (Cooke and Massee).

(2) Helminthosporium torulosum (Syd. Ashby, Comb, Nov). Cercospora musarum (Ashby).

(3) Macrophoma Musae (Cke, Berl and Vogl).

(4) Terticillium Sp.

5) Thielaviopsis paradoxa (Von Hohnel). 
Various species of Fusarium have been recorded as saprophytes.

Of these fungi, Gloeosporium musarum alone appears to have been described at length as an important cause of disease in storage or transport. Terticillium, Gloeosporium, and Fusarium have been recorded by Simmonds* as the organisms associated with Stem-end Rot. As a resumé of the literature on these several fungi has been set out elsewheret it need not be repeated here.

\section{Establishment of Infections.}

Fungal spores may be deposited on the bunches either in the field or in the storage chamber during transport. The organisms so far isolated are freely dispersed in Nature, and several of them, e.g., Thielaviopsis paradoxa, Botryodiplodia theobromae, are well known on other crops in the field. By exposing sterile dishes of culture media in plantations for a few minutes, the prevalence of numerous airborne spores is readily demonstrated. On two occasions sets of a half-dozen petri dishes ( 4 inches in diameter) of malt agar and potatosaccharose agar were exposed in plantations for five minutes on days when fruit was being reaped. After culturing for three days, the first set of six plates showed the following number of fungal contaminations: $50,1 \overline{5}, 3 \overline{5}, 11,21,27$. The second series gave similar counts. Infections may, therefore, be regarded as being in many instances established in the field. As a considerable amount of disease usually becomes manifest, even at the low temperature of transport $\left(53^{\circ} \mathrm{F}\right.$.), the holds may, after carrying a few consignments, become contaminated, while ample opportunities for spore dispersal are afforded by the cooling system in which air is blown through the stored fruit.

\section{Rate of Groweth of Fungi at Different Temperatures.}

Growth studies were carried out by culturing the fungi on 3 per cent. malt extract agar in petri dishes. As all the organisms studied grow well on this medium, growth rate was readily ascertained in the usual way, by measuring the diameter of the colony from day to day. Rate of growth was determined for four temperatures, namely, room temperature ( $7 \mathrm{~S}^{\circ} \mathrm{F}, 82^{\circ} \mathrm{F}$. approximately), cool transport

* Simmonds, J. H. : Loc, cit.

+ Wardlaw, C. W: : Banana Fruit Diseases. A Reriew of the Literature on Fimgal I)iseases of Banana Fruits. Trop. Agric., VII, Xi), 5, 1931). (Sice Appendix.) 
temperatures $\left(55^{\circ} \mathrm{F}\right.$. and $60^{\circ} \mathrm{F}$ ), and ripening room temperature $\left(70^{\circ} \mathrm{F}\right.$.). (As measurements were obtained from petri dish cultures kept in the Storage Chambers, in which at times slight fluctuations in temperature may take place, the growth curves may suffer slightly in accuracy. For all practical purposes, however, this is not significant.)

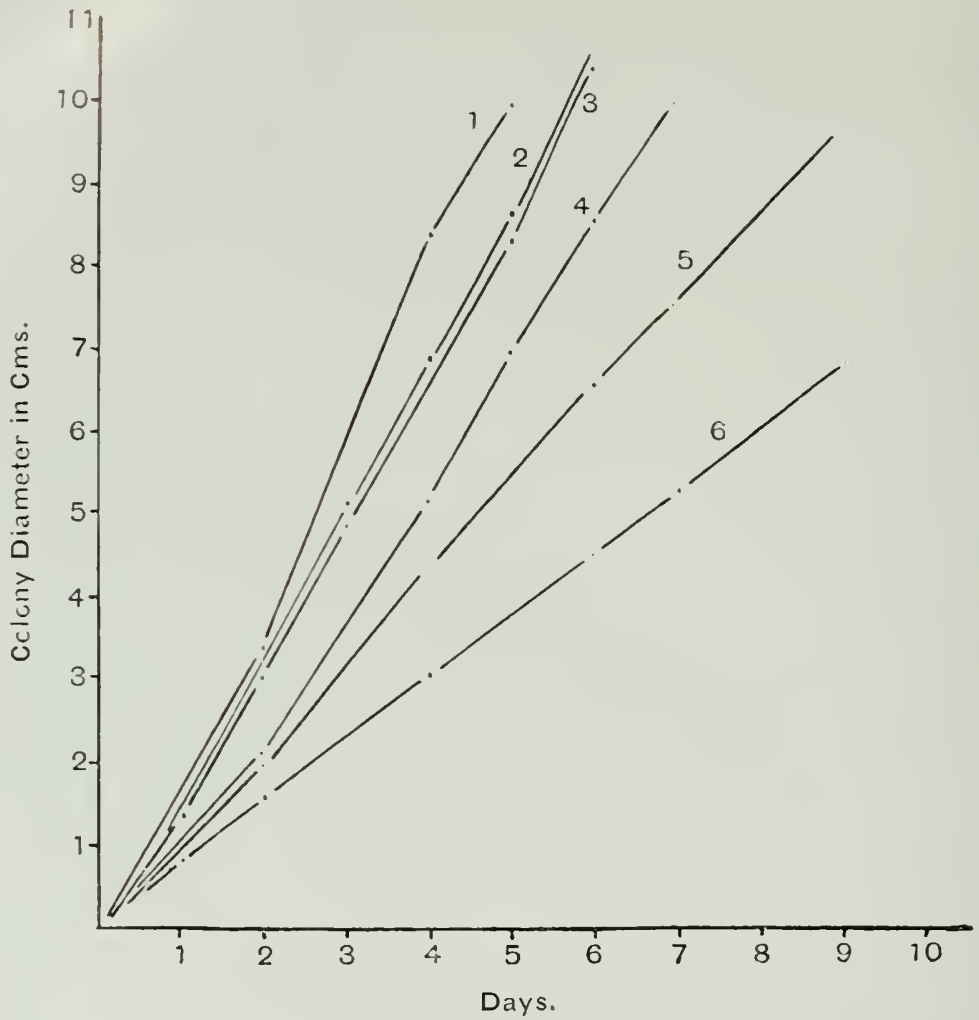

Fig. 13.-Growth Curves of Fungi at 78 F. -82 F. 1. Thielaviopsis; 2. Gloeosporim (Strain B) ; 3. Phomopsis; 4. Gloeosporium (Strain A) ; 5. Fusarium sp.; 6. Fusarium sp.*

Figs. 13 and 14 show the growth curves for six fungi at $78^{\circ} \mathrm{F}$. and $55^{\circ} \mathrm{F}$. In Fig. 13 (at room temperature) the highest growth rate is exhibited by Thielaviopsis, which traverses the surface of the culture

In the graphs presented in this paper the vertical axis gives the diameter of the culture in cms., and the horizontal axis the time in days. 
medium at the rate of more than 2 cms. per day. Glocosporium (Strain A) occupies an intermediate position, while the two species of Fusarium examined showed relatively slow rates of growth, viz., $1 \mathrm{~cm}$. per day and less. The curves in Fig. 14 provide an interesting contrast. At the lower temperature of $55 \mathrm{~F}$. there is a marked reduction in rate of growth. Thus, Thielaviopsis, with the steepest curve indicating a growth of $1 \cdot 2 \mathrm{cms}$. per day, stands distinctly apart from the others. The latter are grouped together in a close assemblage,

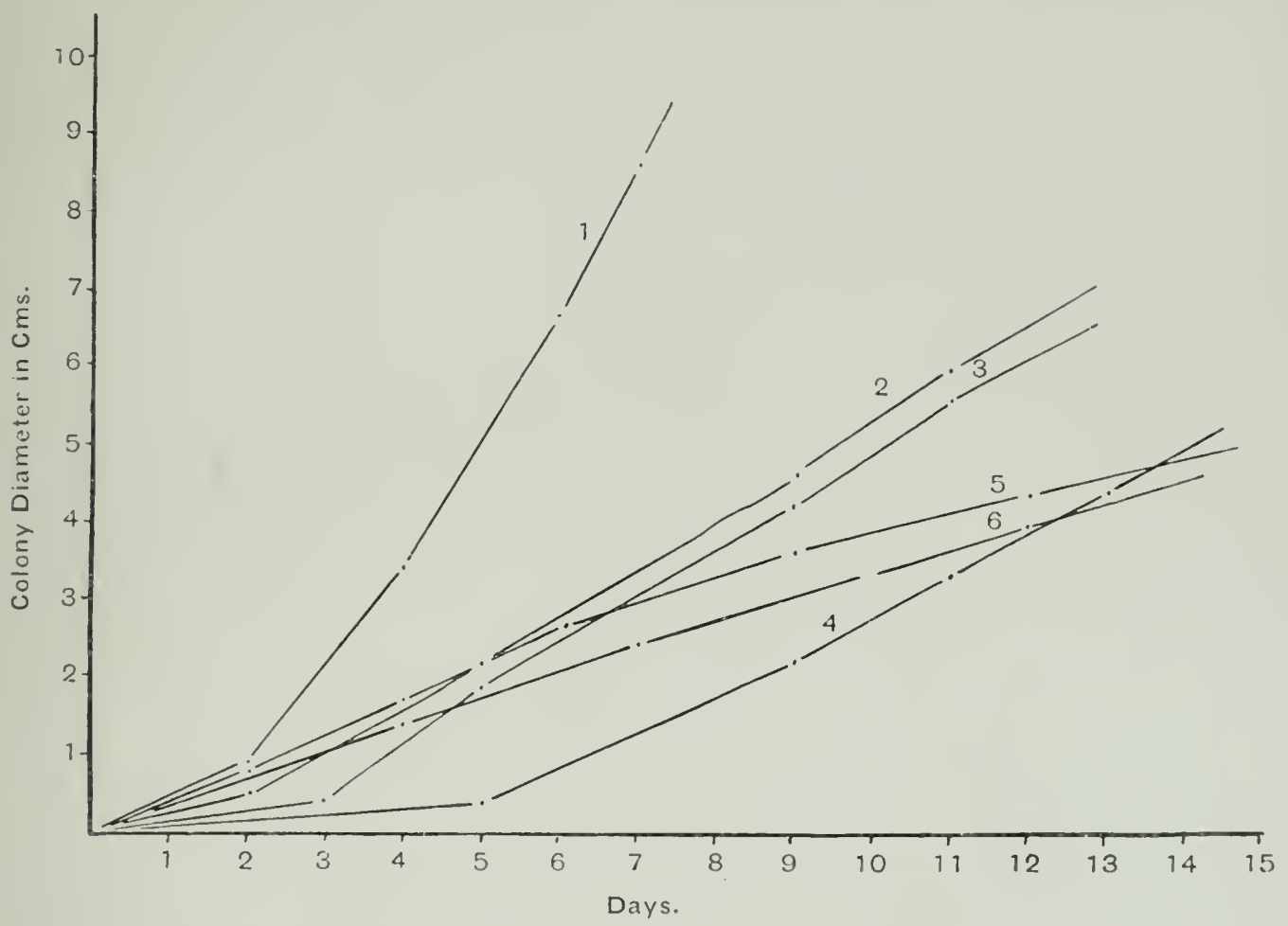

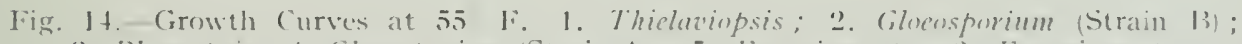
3. Phomonpsis; 4. Goloesporium (Strain .1): 5. Fusarium sp.; 6. Fusarium sp

and represent growth rates varying from $(0.33$ to $0 \cdot 54$ cms. per day. This high growth rate of Thiclaviopsis has important corollaries when its parasitism is considered. Further, it will be seen that while Gloeosporium (Strain A) has a higher growth rate than either of the two species of Fusarim, ret its curve at 55 li, does not cut the 
Fusarium curves till a relatively late stage, i.e., till the twelfth and thirteenth days. This is due to a pronounced initial lag at low temperature ; it will be seen that no measurable growth takes place until the fourth or fifth day. A slight initial lag is also shown by the other fungi, with the exception of the two species of Fusarium. Figs. 15 and 16 show growth curves for Thielaviopsis and Gloeosporium at different temperatures. In Fig. 15 it will be seen that the initial lag increases with reduction in temperature. The lowest curve shows

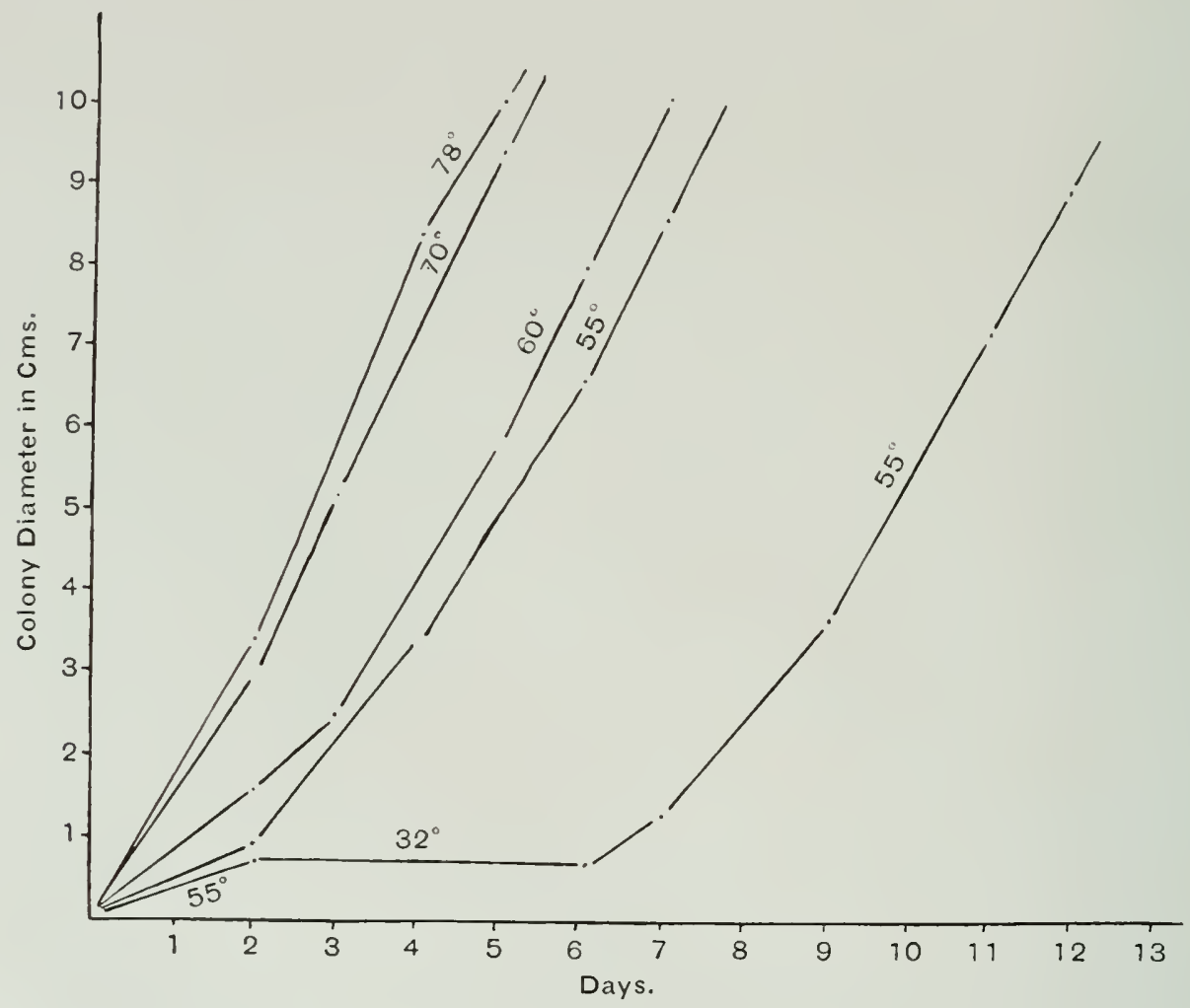

Fig. 15.-Growth Curves for Thielaviopsis paradoxa at $78^{\circ}, 70^{\circ}, 60^{\circ}, 55^{\circ}$ and $32^{\circ} \mathrm{F}$.

the record of an experiment in which a culture, after being started off for two days at $55^{\circ} \mathrm{F}$., was placed for four days at $32^{\circ} \mathrm{F}$. No growth took place, but on being removed to $55^{\circ} \mathrm{F}$. again, growth was renewed and a characteristic $55^{\circ} \mathrm{F}$. curve obtained. Fig. 16 indicates clearly the increasing significance of an initial lag with reduction of 34 
temperature. Thus, at the end of eleven days, it is mainly responsible for the difference of $2 \mathrm{cms}$. between the growth at $55^{\circ} \mathrm{F}$. and $60^{\circ} \mathrm{F}$. The presence of an initial lag has important implications in relation to the establishment of fungi during the first days of transport, i.e., when the fruit is being cooled down from normal air temperatures to the cool temperature of the hold.

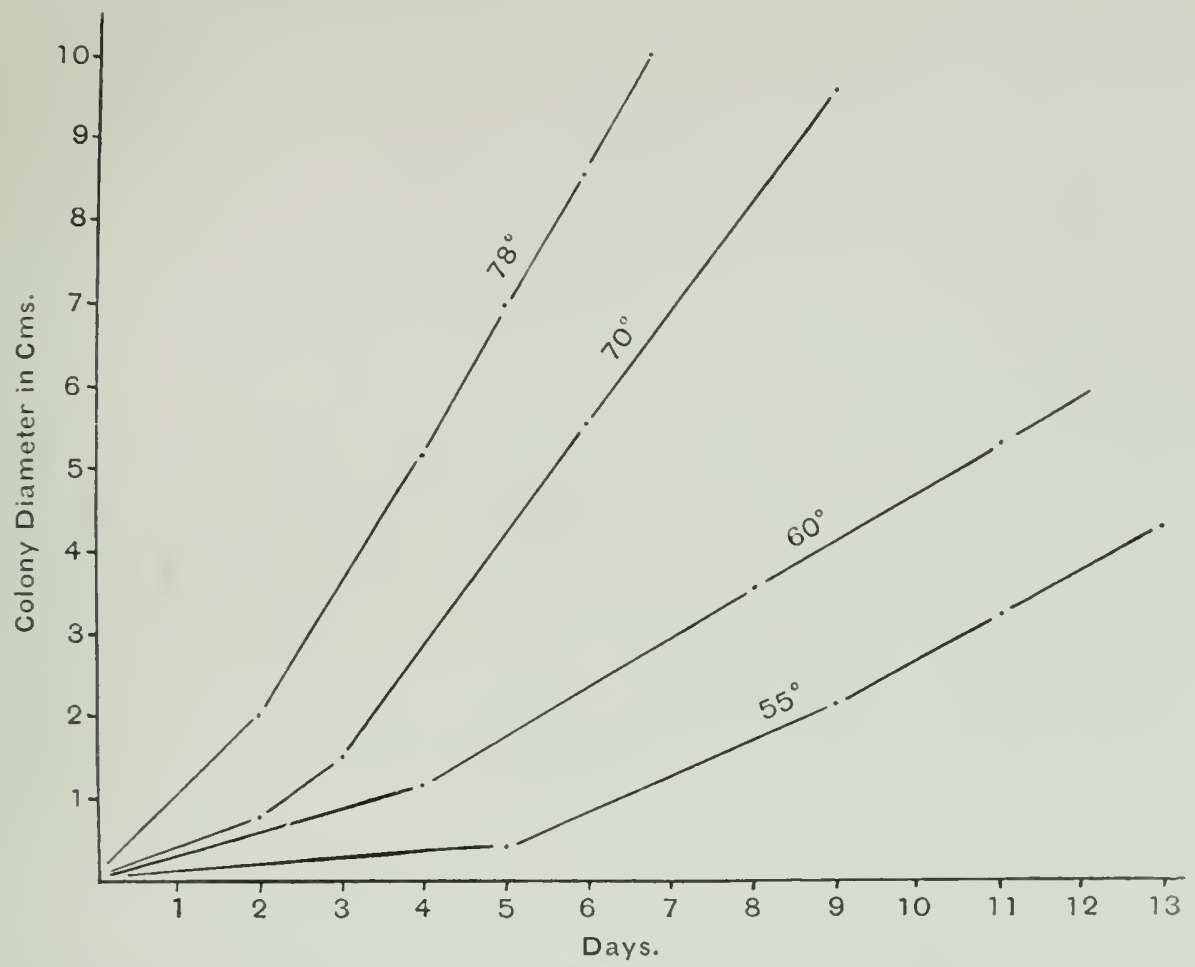

Fig. 16. -Growth Curves for Glocosporium musamm (Strain A) at $78,71^{\circ}, 60^{\circ}$, and $55^{\circ} 1^{\circ}$.

I. Inoculation Experiments.

To investigate the parasitic behaviour of the iungi isolated, inoculation experiments were carried out along the following lines :-

(1) Main-stalk Inoculations.-At the time of reaping, main stems were cut rather longer, so as to provide material for these experiments. The stems were cut into pieces six to nine inches long, superficially sterilised for five to ten minutes in $0 \cdot 2$ per cent. mercuric chloride solution, and washed twice in sterilised water. 
Using the method of Granger and Horne,* plugs were removed from the middle of the stem by means of a sterilised cork-borer. The plugs were then inoculated, replaced, and sealed with a smear of sterilised raseline. Before being placed in the container, the ends of the stem were cut off with a flamed knife and smeared with raseline. The object of these inoculations was to determine which organisms played the major part in producing main-stalk rot.

(2), (3) and (4) Fruit Inoculations.--Single hands of fruit were carefully selected and sterilised as above.

(2) Some hands were cut so that a short length of main-stalk was left. Using the cork-borer as before, this material was inoculated just above the cushion ; the stem ends were cut with a flamed knife and smeared with raseline. The object of this experiment was to produce the local lesions frequently observed in the ricinity of cushions.

(3) Finger and finger-stalk inoculations were carried out by placing a spore suspension or a piece of solid inoculum (on an agar medium) on the surface of the fruit at the distal end and on the finger-stalks. These experiments were intended to test the direct penetrating power of different fungi into maturing fruit.

(4) The above experiment was extended as follows:- Prior to the application of the inoculum, alternate fingers were stabbed or scratched with a sterilised needle at the distal end of the fruit and on the finger-stalks, to test the activity of the fungi as wound parasites.

Both stems and hands were enclosed in large glass desiccators of approximately 28 litres capacity. These were sterilised by washing with 0.2 per cent. mercuric chloride solution. Each container was supplied with a small beaker or tube containing soda lime to take up the carbon dioxide. The atmosphere in the jars was sampled at regular intervais and analysed by means of a Haldane Gas Analysis Apparatus, and was found to be comparable with that of the storage chamber. The principal point of divergence between conditions in the containers and the storage room lay in the higher humidity of the former. No attempt to reduce this was made, as the higher humidity would favour the growth of fungi. During the experiments Granger, K., and Horne, A. S. : A Method of Inoculating the Apple. Ann. Bot., $38,1924$. 
the desiccators were kept in the storage rooms; the observations recorded, therefore, refer to the parasitic behaviour of the several fungi during the period of cool storage and the period of ripening at a higher temperature. Where positive results were obtained, the organisms were re-isolated from the affected tissue and again identified. Control hands ripened up quite normally in the jars.

The results of inoculation experiments may now be briefly discussed.

\section{Thiclaviopsis paradoxa (I on Hohnel).}

This organism was isolated from severe cases of main-stalk rot of Gros Michel during storage trials. The fungus, which is well known as the cause of pineapple disease, has also been isolated from diseased tissues of sugar cane, coconut, and other palms, and several other crop plants. Ashby* has described the isolation of this organism from a "Blackhead" disease of the banana sucker in Jamaica,while Roldan† makes a brief reference to its power of attacking banana fruit; more recently Hansford has reported this organism as the callse of a rot of damaged banana fruit in Uganda.

The writers' incoculation experiments have shown Thiclaviopsis paradoxa to be an important parasite on main-stalks and fruit of the Gros Michel and other banana varieties. Inoculated pieces of mainstalk underwent a rapid decay; the tissue became blackened and softened, and a characteristic sweetish odour was liberated. At an early stage the fungus grew out through the epidermis and formed a cobweb-like mass of dark coloured mycelium. As the fungus appears to grow through the main-stalk at practically the same rate as it covers the surface of a farourable artificial culture medium, and as its intrinsic rate of growth is high even at reduced temperatures, the amount of rot produced may be very considerable during the period of cool storage.

When the fungus was inoculated into the main stem in proximity to a hand of fruit, the amount of damage sustained before the normal period of handling had elapsed was very considerable (Fig. 17). The main-stalk quickly rotted, and the fungus then passed through the cushion to the finger-stalks and fingers. The finger-stalks became

* Ishby. S. I. : Banana Discases in Jamaica. Bull. Jept. Agric. Jamaica, Vol. Il. No. 6, 1912.

+ Rolkan. E: F. : The Soft Rot of Pineapples in the Philippines and ()ther countries. Philippine Agriculturist, Vul. XIII, 1925.

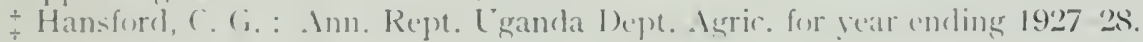




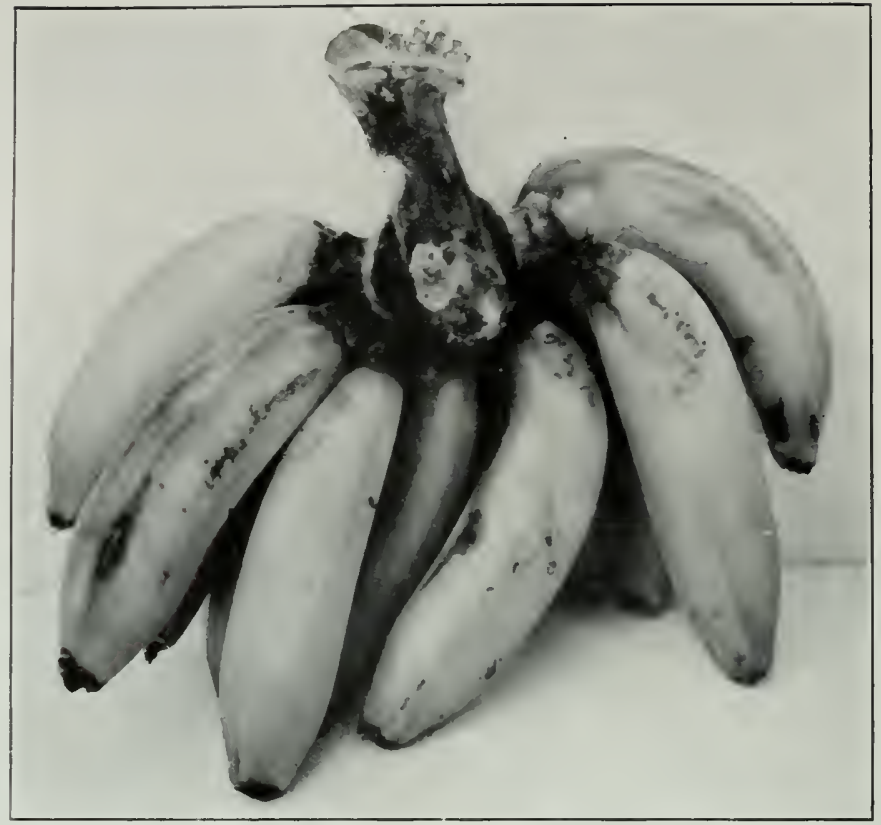

Fig. 17.--Disease effects produced by inoculating a cushion with Thielaviopsis paradoxa.

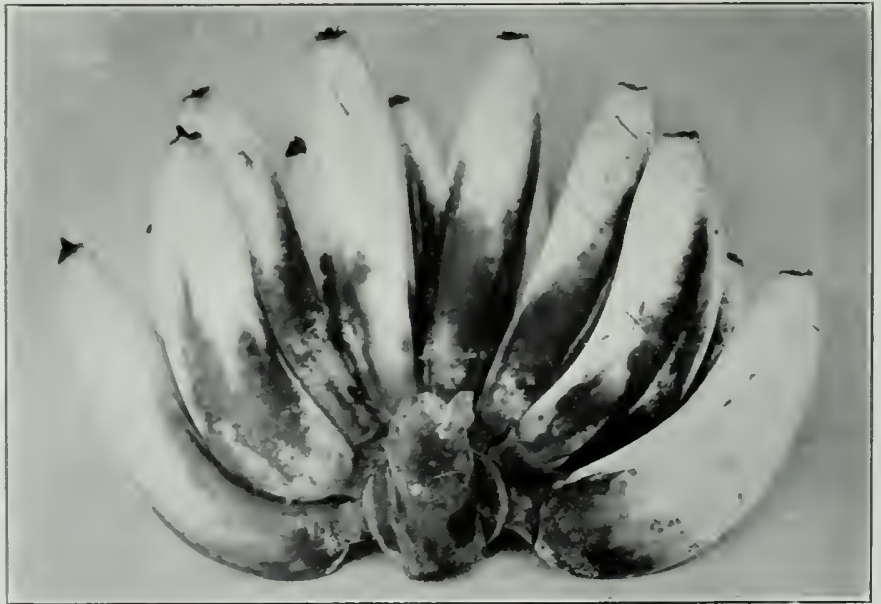

I1g. 18.-Advanced stage of infection resulting from a cushion inoculation with Thielariopsis paradoxa. 
dark in colour, and outgrowing masses of mycelium came into evidence. The spread of the fungus into the fruit caused an uneven black discoloration of the skin (Fig. 18), and reduced the pulp to a dark brown, soft and wet consistency. Once the finger-stalks had

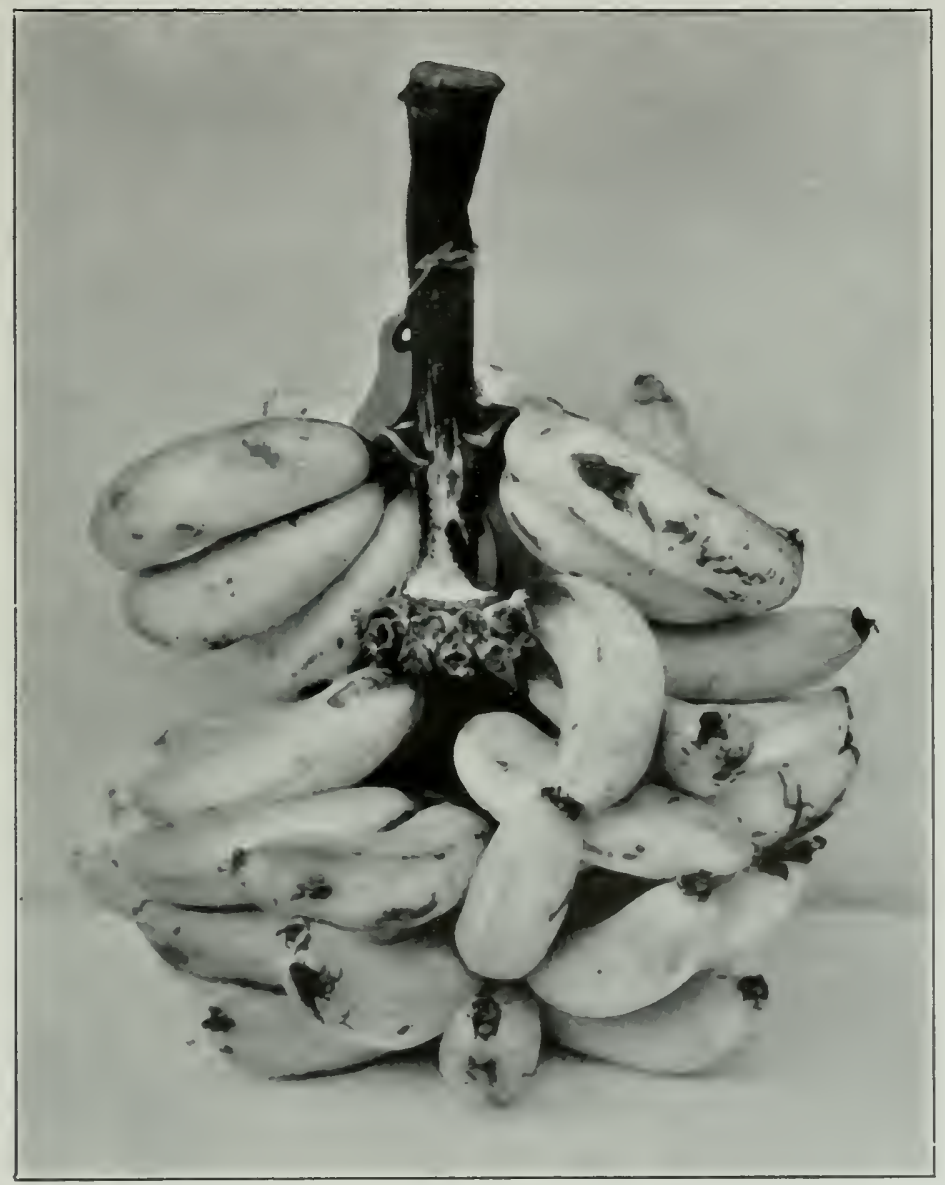

ligg. 19.-Finger-dropping resulting from inoculating main stalk with Thiclarupsis paradexa. The shrunken stem and general disorganisation of fingers are also shown.

been invaded, the fruit could not be handled without fingers dropping off. The experiment was then extended by inoculating the stems of suspended bunches between the top and second hands. A characteristic result is shown in Fig. 19, where, before the conclusion of the 
normal period of handling, an important amount of main-stalk rotting had taken place, accompanied by fruit decay and finger-dropping. The illustration shows that all the fingers below the point of inoculation have dropped, while other finger-stalks in close proximity are diseased and blackened. These parasitic activities frequently induced a premature ripening of fruit.

When spores of Thielaviopsis were applied to unwounded fruit, positive results were not obtained. Its importance, therefore, lies in its behaviour as a wound parasite. While these experiments are capable of considerable elaboration, the results obtained indicate definitely the importance of this fungus as a parasite on the banana during transport, even at cool temperatures. In practice, the bunch may become infected in the field, or infection may take place in the ship's hold if similarly diseased fruit has been previously transported.

The results of these experiments indicate clearly that a severe infection with Thielaviopsis paradoxa in bulk storage will undoubtedly constitute a grave menace.

\section{I'II. Gloeosporium musarum (Cooke and Massee).}

This organism has a wide geographical distribution, and is already well known as a parasite on banana fruits and stems. Agati* has shown that in the Philippines the fungus is responsible for a considerable amount of damage in the field. Toro'st account, based on work in Porto Rico, and most other researches, refer to this fungus as a parasite on storage fruit at maturity. So far, Trinidad fruit has not shown this disease in the field, but it has been of frequent occurrence on fruit and stems during the later stages of ripening. Two strains, $A$ and $B$, have been isolated. The former appears to be the more common. It has already been seen that at cool temperatures this organism experiences a marked initial lag; sooner or later, however, it inevitably makes its appearance under storage conditions. It most commonly occurs on the finger stems of the top hand, the outermost fingers showing the greatest amount of infection. The first indication of parasitic activity consists in the development of brownish circular blemishes on the finger-stalks. These increase in size, become dark in colour and sunken, and finally change to a rusty or salmon colour as the acervuli or masses of conidia make their appearance. At this

* Agati, J. A. : Banana Stem and Fruit Rot. Philippine Agriculturist, 1922.

Toro, R. A. : Studies on Banana Anthracnose. Jour. Dept. Agric., Porto Rico, 1922.

40 
stage, if the infection is well advanced, finger dropping takes place when the fruit is handled. The fruit flesh itself, howerer, is only affected to a slight extent by the fungus, and when the diseased skin is removed the underlying fiesh is usually found to be quite sound, except in cases of serere infection. The fungus may also become established at the distal end of the fingers. From there it slow!y spreads, producing characteristic blemishes. Again the underlying flesh is usually found to be sound. Such blemishes, though superficial, detract from the appearance of the fruit, and may, in cases of adranced infection, give trouble in handling. So far, the excessive spotting indicative of numerous local infections, as described by other workers, has not been observed during our storage trials. When the fungus attacks the main-stalk it spreads slowly through the tissues, causing a discoloration which becomes apparent through the epidermis. Sooner or later its presence is definitely indicated by areas covered with the characteristic salmon-coloured spore masses. These activities are frequently accompanied by a characteristic splitting of the stem.

Inoculation Experiments (Strain A).-This strain is characterised by a relatively scanty mycelium and very abundant large spore masses of a yellow-salmon colour. Fig. 20 shows the type of mainstalk rotting produced by this organism during a storage trial, and the superficial production of a zone of acervuli. The illustration also shows the characteristic infection of two of the outermost finger-stalks. Fig. 21 shows a typical split stem also resulting from artificial inoculation.

Positive results were obtained when the fungus was inoculated on to either wounded or unwounded finger stems and finger ends. Fig. 22, in which alternate fingers were stabbed with a needle before inoculation, shows that in maturing fruit most inoculations have caused some damage; this, however, is much more extensive in the presence of wounds or bruises. The right hand finger, in which the infection has reached an advanced stage, shows finger-dropping as the result of infection. It will be noted, however, that the spread of the fungus to the fruit is slow, and that little internal damage is accordingly sustained. Fig. 23 shows the result of inoculating wounded and unwounded finger-stalks and fingers. While some inoculations did not give positive results, others showed that the fungus can attack banana tissue at certain stages of maturity, even in the absence of wounds. As the illustration clearly shows, however, 


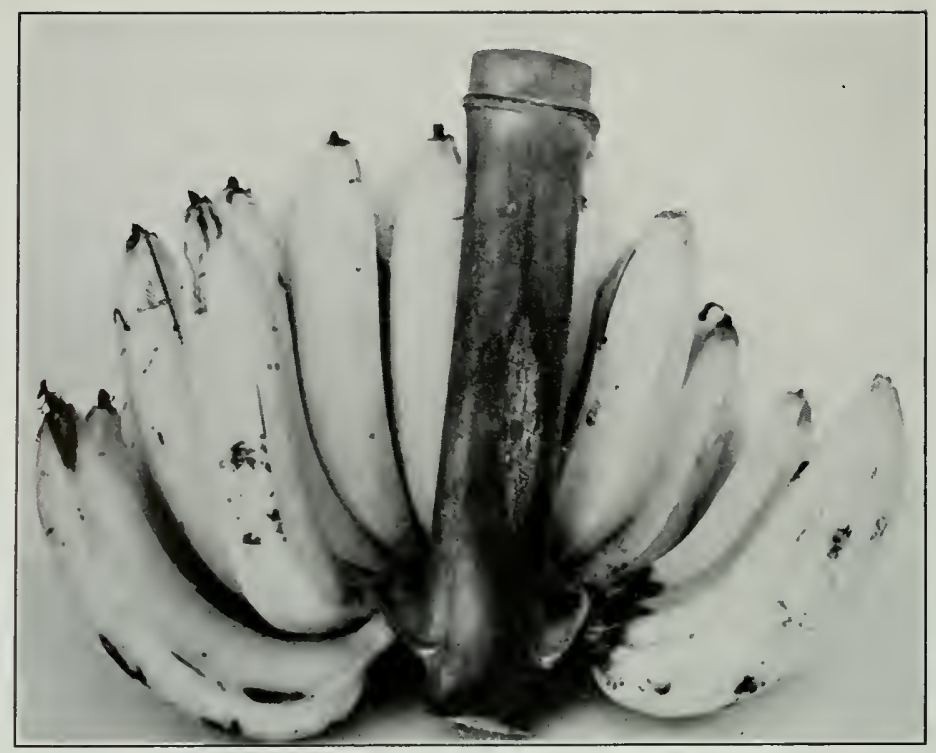

Fig. 20.--Lesion produced on main-stalk by inoculation with Glocosporium musurum. Finger-stalk Rot is also present on right hand fingers.

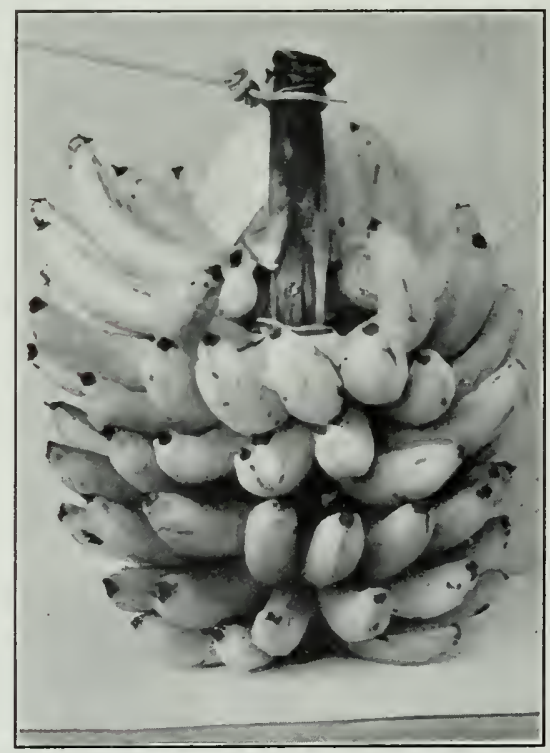

Fig. 21.-Local Lesion and Stem Splitting produced by an inoculation with Gloeos porium 


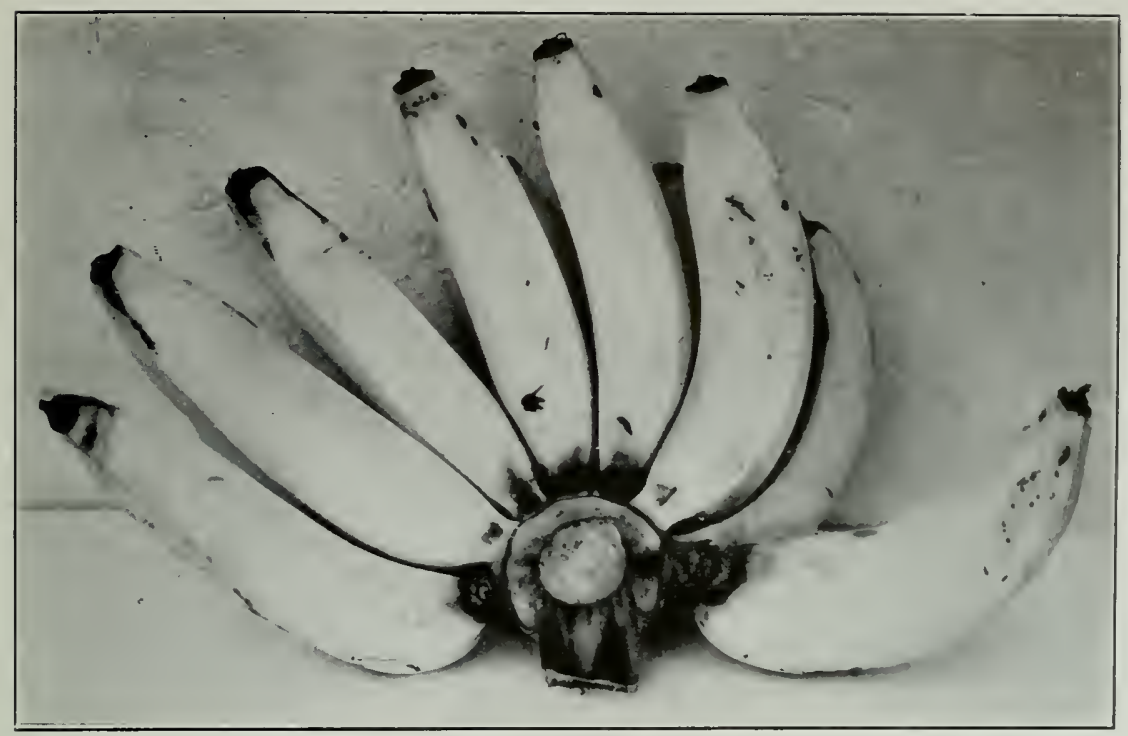

Fig. 22.-Finger-stalk Rot produced by Glocosporium musarum on wounded finger-stalks. Every second finger was left unwounded. Note finger-dropping on right and its commencement on left.

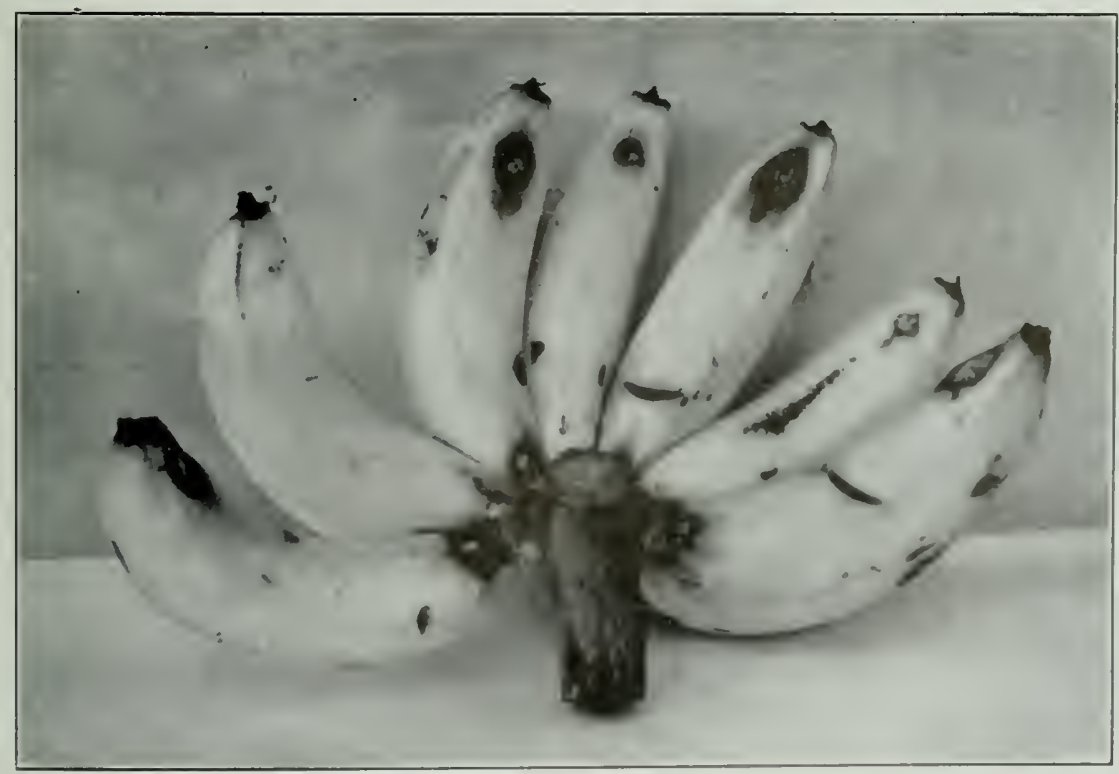

Fig. 23.-Finger-Stalk and Finger Inoculations with Cilternsorimm musurum. Divery second finger was left unwounderl, but most of the inoculations have given positive results. 
these are less extensive. On this subject it has been stated by Delacroix* and others that Gloeosporium musarum is a wound parasite, and that it can only cause banana anthracnose when the fruits have been injured. Toro's inoculation experiments showed that the fungus cannot enter uninjured green or partly matured fruit in the field, even of the most susceptible varieties. On the other hand, completely matured bananas, when placed under proper conditions, became diseased, whether injured or not. This observation has been correlated with important changes in the chemical and physical constitution of the peel. Toro also demonstrated that the mycelium of Gloeosporium musarum secretes an enzyme which dissolves the parenchymatous tissue of mature fruit, but which has no apparent effect on unripened bananas or on the epidermal tissue of either immature or mature fruit. He postulates mechanical injury accompanied by softening of the peel, with an increase in sugar content, as being important conditions making for infection.

(Strain B).-This strain, which sometimes accompanied Strain A, was characterised by more rapid growth and more abundant mycelium. Sporulation, on the other hand, was relatively weak on many media. Vegetatively, this strain was easily distinguished by the formation of well-marked appressoria.

Positive results were again obtained from main-stalk and cushion inoculations. In the absence of wounding there was no penetration of the epidermis of fingers or finger-stalks, but after a slight scratching with a needle, a considerable amount of infection took place. The skin of the fruit developed a black colour, and became slightly sunken, but the underlying flesh was not greatly affected. Typical infections resulting from inoculation are shown in Fig. 24.

\section{B. Botrvodiplodia theobromae (Pat).}

Well known in the Tropics as a wound parasite, this organism was frequently isolated from the rotted main-stalks of several varieties, and also from diseased finger-stalks of the Bumulan and blackened finger-tips of the Lacatan. Positive results were obtained from mainstalk inoculations. Fig. 25 shows the rotting produced after five days at $55^{\circ} \mathrm{F}$. The affected tissue developed a characteristic water-soaked appearance, accompanied by decided blackening, softening, and splitting of the stem. As this organism grows very rapidly, it is

Delacroix, G. O.: Bull, de la Soc. Mycol. de France, XIIIII, 1902. 
capable of causing a consiclerable amount of main-stalk rot. Finger and finger-stalk inoculations, even in the presence of stabs or scratches, only resulted in minor blemishes.

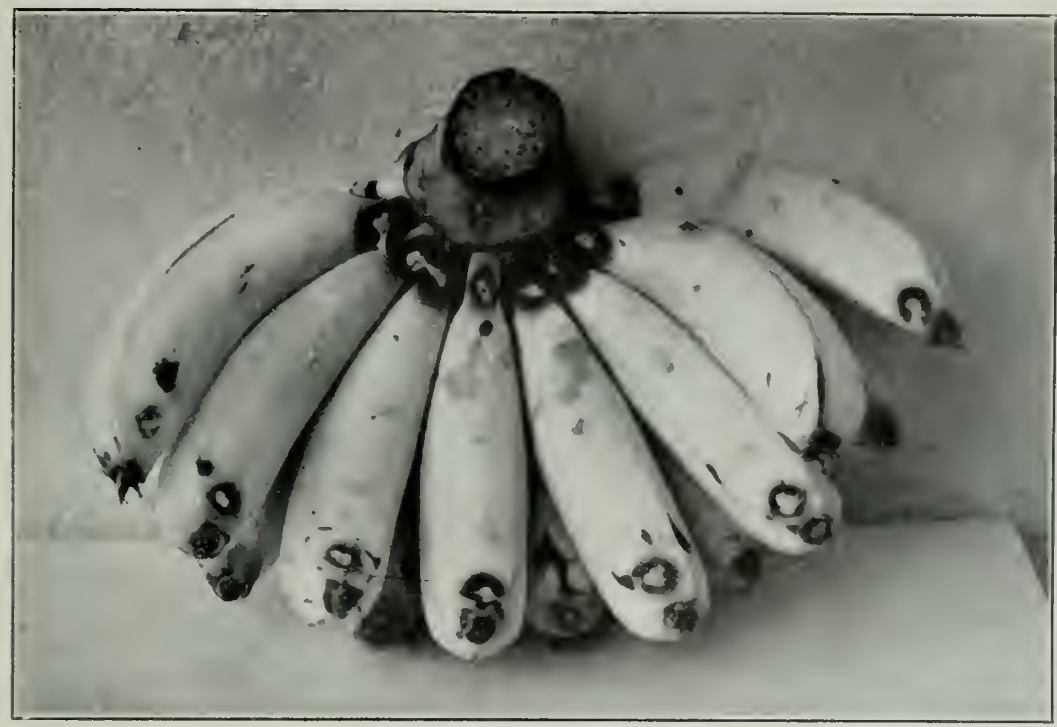

Fig. 24--Finger Stalk and Finger Inoculations witl Gloeosporium musamm (Strain B). The skin was scratched before inoculation, and it will be seen that positive results were olstained in all but one finger end. Spores applied to uninjured tissue mid-way in cach finger gave negative results.

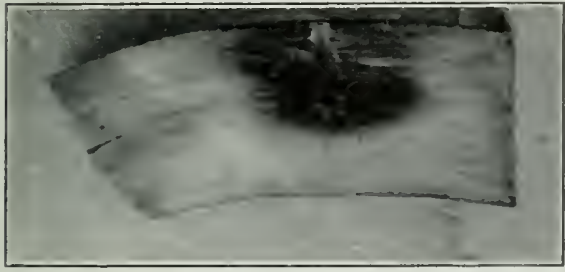

Iiig. 25. -NIain-stalk Rot (an early stag(e) produced by Botryodiplodia thenbromat.

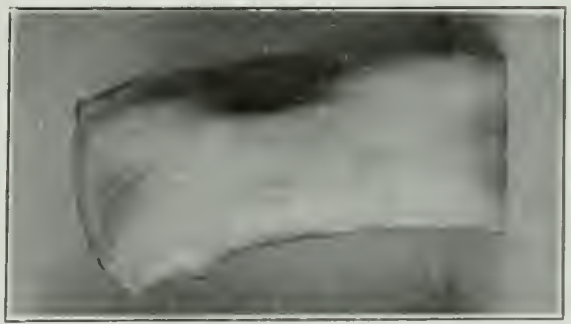

Fïg. 2ti. - Main-stalk liot produced lu. Plhumupsis sp.

I.I. Phomopsis sp.*

This organism was isolated on several occasions in pure culture from local lesions of main-stalks, and also from blackened finger tips.

* Irovisional identification. 
Positive results were obtained from main-stalk inoculations (Fig. 26), but no effective parasitism was shown by any of the inoculations of finger stalks or fingers, even in the presence of wounds. Mr. S. F. Ashby of the Imperial Bureau of Mycology informs us that he has a similar culture isolated from a fruit-stem rot of bananas in the Canaries.

\section{Fusarium spp.}

During this investigation, various species of Fusarium were frequently isolated from diseased main-stalks and fingers. A number of species have been described by Reinking and Wollenwebber* and Hansford $\dagger$ from such sources. Two species tested by us were not found to be actively parasitic on either main-stalks or fruit. Such saprophytes may, however, be of considerable importance in so far as they accentuate the preliminary damage caused by the original parasites. Thus, Ogilvie $\ddagger$ found that Cercospora musarum, the organism causing Black Tip of the Cavendish banana in Bermuda, was frequently overgrown and obliterated by species of Fusarium.

\section{Discussion.}

This brief account by no means covers the mycological aspect of banana stem and fruit rots in storage, and doubtless other organisms will be isolated from time to time and found to be pathogenic to maturing fruit. Taken collectively, however, the observations submitted definitely indicate the nature of the problem and take cognisance of a number of organisms frequently associated with fruit and stem rots in cool storage. Further, a number of the more important and characteristic rots have been reproduced by pure culture inoculation experiments under conditions closely approximating to those in operation during the actual storage trials.

In the production of storage rots, many organisms are involved whose activities differ in degree and in kind. As already indicated, the mycological aspect of the problem may justly be regarded as beginning in the field, since most of the organisms involved, such as Thielaviopsis, Gloeosporium, Botryodiplodia, Fusarium, etc., are of general distribution, and may effectively parasitise other hosts also. The opportunities for fungi becoming established in the field are

* Reinking, O. A., and Wollenwebber, H. W. : Tropical Fusaria. Philippine Jour. of Science, Vol. 32, 1927.

$\uparrow$ Hansford, C. G.: The Fusaria of Jamaica. Kew Bull. Misc. Inf., 1926.

Ogilvie, L.: "Black Tip," a Finger-tip Disease of the Chinese Banana in Bermuda. Phytopath, XVII, 1928.

46 
numerous, since not only may spores be wind-blown, but they may also be carried and lodged by the numerous animal agencies associateil with the developing bunch. Such agencies are also responsible for the causation of wounds through which effective parasitisn may take place.

The downward spread of a severe infection from the cut end of the main-stalk may have serious results, and, in point of fact, Stem-end Rot of fruit at English ports falls into this category. The shorter the stem the sooner will it be exploited by invading organisms. This has a direct practical corollary. Where for experimental purposes the stem at the top of the bunch was left rather longer, fungal penetration did not approach so closely to the fruit, and such bunches gare little or no trouble in handling. In large consignments, long stems are, of course, inadmissible, but there is much to be said for a stem of intermediate length. The minimising of fungal penetration effected by cutting stem ends with a sterilised knife and sealing with vaseline, have been discussed elsewhere.

Disease of fingers in carefully-handled small consignments was of limited extent. Even there, however, a certain amount of infection by Gloeosporium was present, but, taken as a whole, this was negligible. Wherever the fingers had received bruising in transport, however, the incidence of disease increased considerably. This was especially true of thin-skinned, readily injured fruits, such as the Lacatan. Here, even though considerable care had been exercised, the amount of infection caused by Gloeosporimm and other organisms, frequently caused the fruit to be decidedly unsightly.

\section{Summary.}

1. Wastage in banana cargoes or in stored fruit is due mainly to the activities of a number of fungi or moulds. These are responsible for an important downward rotting of the main-stalk, for finger-(lropping, and the blemishing and rotting of fruit.

2. Infections may become established in the field or during storage. Rough handling of fruit with the consequent bruising greatly accentuates the amount of disease.

3. Temperature plays an important part in the growth activities of moulds. Low storage temperatures curtail the amount of disease.

4. Typical diseases were obtained when some of the fungal organisms which had been isolated were inoculated into sound mainstalks and fruits. Mounding was nsually an important accessory condition in the production of disease. 


\section{APPLICATION TO TRANSPORT.}

Our earlier investigations at the Low Temperature Station indicated that decay of banana fruit during cool storage was referable to a plurality of organisms. Where fruit was carefully handled and placed in the cool chamber with the minimum delay, the amount of disease developed at the end of a storage trial was relatively insignificant and seldom gave trouble in handling.

The next stage in the investigation was to consider the nature and incidence of diseases in large consignments of fruit during ocean transport. The following observations are the result of several visits at Port of Spain to fruit ships, through the courtesy of Messrs. Elders and Fyffes, Ltd. These ships are charged with bananas at Santa Marta, Colombia, and take three days to reach Trinidad.

\section{General Observations.}

For several vears a disease known as Stem-end Rot has been prevalent in cargoes on arrival at the English port. Using the writers' terminology, this disease would be described as Main-stalk Rot. Apart from the direct loss due to early ripening or advanced decay, a considerable amount of difficulty is experienced in the subsequent handling of those bunches whose main-stalks are in a rotted or partially rotted condition. As the cut banana main-stalk at maturity provides a suitable nutrient substratum for many fungal organisms, a certain amount of decay is always present, but unless this becomes extensive, it is not a limiting factor in handling the bunches. On general mycological grounds, the amount of main-stalk rot developed depends on sereral factors, including :-

(1) The pathogenicity of the fungal organisms present.

(2) Their rate of growth.

(3) The length of stem to be traversed.

(4) The length of time that elapses before fruit is brought down to the cool temperature of transport.

(5) Duration of voyage and temperature of holds.

(6) Duration of ripening period and temperature and humidity of ripening room.

II. Isolation of Organisms.

Pieces of infected main-stalk were removed from the holds and isolation of fungi carried out. The following were obtained:Botryodiplodia theobromae, Thielaviopsis paradoxa, Gloeosporium musarmm, and species of Pestalozzia, Fusarium, Eurotium, and Mucor, and several unidentified fungi. It will be seen that the list includes a 
number of organisms already found and investigated in our earlier storage trials. As Botryodiplodia was much in evidence, and as it showed very vigorous growth in culture, its pathogenicity was again tested out, using the four methods of inoculation already clescribed. On examination of main-stalk inoculations after five days at $55^{\circ} \mathrm{F}$., considerable rotting had already taken place, while at the end of twelve days this was greatly accentuated, and cracks began to appear in the vicinity of the infected tissue - a characteristic feature of the disease on arrival at Aronmouth. Inoculation of stems just above the cushion gave similar results, accompanied by a decay of the cushion and premature ripening of the fingers. Finger-ends and finger-stalks wounded and inoculated only yielded minor infections.

\section{Discussion of Temperature Relations.}

On inspection of fruit on arrival at Trinidad after the three-days voyage from Santa Marta, it was found that a considerable amount of infection was already present on the cut main-stalks at both the upper and lower ends. Most stem ends showed a covering of mould, and in some the downward rotting had definitely commenced, as indicated by the discoloration and streaky appearance of the first one, two, or three cms. of tissue on cutting. It is important to note that the amount of disease on Santa Marta fruit at the end of three days in storage was greater than that developed in bulk storage trials at the Low Temperature Station at the end of fourteen ans.* An explanation is readily to hand. Generally speaking, the interval between the reaping of Colombian bananas and the commencement of refrigeration, after closing the hatches and blowing out the air thoroughly for one hour, is approximately thirty-six hours, while this interval, in the case of our fruit, has seldom been as much as ten hours. During this period while loading temperatures are in the vicinity of $80^{\circ} \mathrm{F} .85^{\circ} \mathrm{F}$., fungal organisms have favourable conditions in which to establish themselves on the cut ends and commence growth. Great then as the initial advantage of a thirty-six hour period at ordinary temperature is, a further advantage is afforded these organisms during the rather slow cooling down of the cargo to $53 \mathrm{~F}$. during the first four days of the royage. The following interesting average temperatures were obtained on boat " $B$ " :-

\begin{tabular}{|c|c|c|c|}
\hline Air temperature-deliverv & & & 6()$^{1}$ \\
\hline$,, \quad,, \quad$ return & & & $63.7 \mathrm{k}$ \\
\hline sh Temperature - fruit & & & $6(1) 2 \mathrm{~F}$ \\
\hline stalk & & & $6(1 \cdot 2) \quad l i$ \\
\hline
\end{tabular}

* This refers to carefully vaselined stem ends. 
These figures represent the temperature of the cargo at approximately serenty hours after the commencement of refrigeration. Our cooling system at the Low Temperature Station permits of more rapid cooling with the smaller consignments which we handle, and, in consequence, considerably lower flesh temperatures are reached within forty-eight hours.

By way of confirming our diagnosis, a consignment of fruit was subjected to ship's condition in the matter of rate of cooling. They were accordingly brought to the laboratory, stem ends were freshly cut, and some were inoculated with Thielaviopsis and the rest with Botryodiplodia, both of these cultures having been prepared from diseased stem ends obtained on the boat. They were then left in the laboratory at ordinary temperatures for thirty-six hours, after which they were held successively for twenty-four hours at $70^{\circ} \mathrm{F}$., for forty-eight hours at $60^{\circ} \mathrm{F}$, and then transferred to $53^{\circ} \mathrm{F}$. for the rest of the royage period. Before the end of the period at $60^{\circ} \mathrm{F}$-the equivalent of the ship's having reached Trinidad - the condition of the main-stalks recalled very strongly the state of affairs found on the ship. After a few days the characteristic stem-splitting became apparent in the case of stems inoculated with Botryodiplodia, and by the tenth day fungal penetration, in the case of Thielaviopsis, had progressed into the centre of the bunch. There is no necessity, therefore, to comment on the pathogenicity of these organisms when favoured with a long period at ordinary temperatures, supplemented by a comparatively slow cooling down of the cargo, as will be seen from the growth curves in the following section.

\section{Growth Curves.}

The growth curves in Figs. 27 and 28, illustrate the behaviour of Glocosporium and Botryodiplodia (isolated from cargoes) at different temperatures. At room temperature $\left(78^{\circ} \mathrm{F} .-82^{\circ} \mathrm{F}\right.$.) the curve for Glocosporim (Fig. 27) ascends fairly steeply, and at the end of six days the colony has reached a diameter of $10 \mathrm{cms}$. A second series of culture was grown for three days at $78^{\circ} \mathrm{F},-82^{\circ} \mathrm{F}$, and then placed at the cool temperature of $55^{\circ} \mathrm{F}$. The first portion of the curve coincides with Curve 1, while the latter part shows the considerably slower growth at $55^{\circ} \mathrm{F}$. Curve 3 shows the growth of imilar cultures placed in $55^{\circ} \mathrm{F}$. from the outset. There is a marked itial lag for the first four to five days, after which there is the 


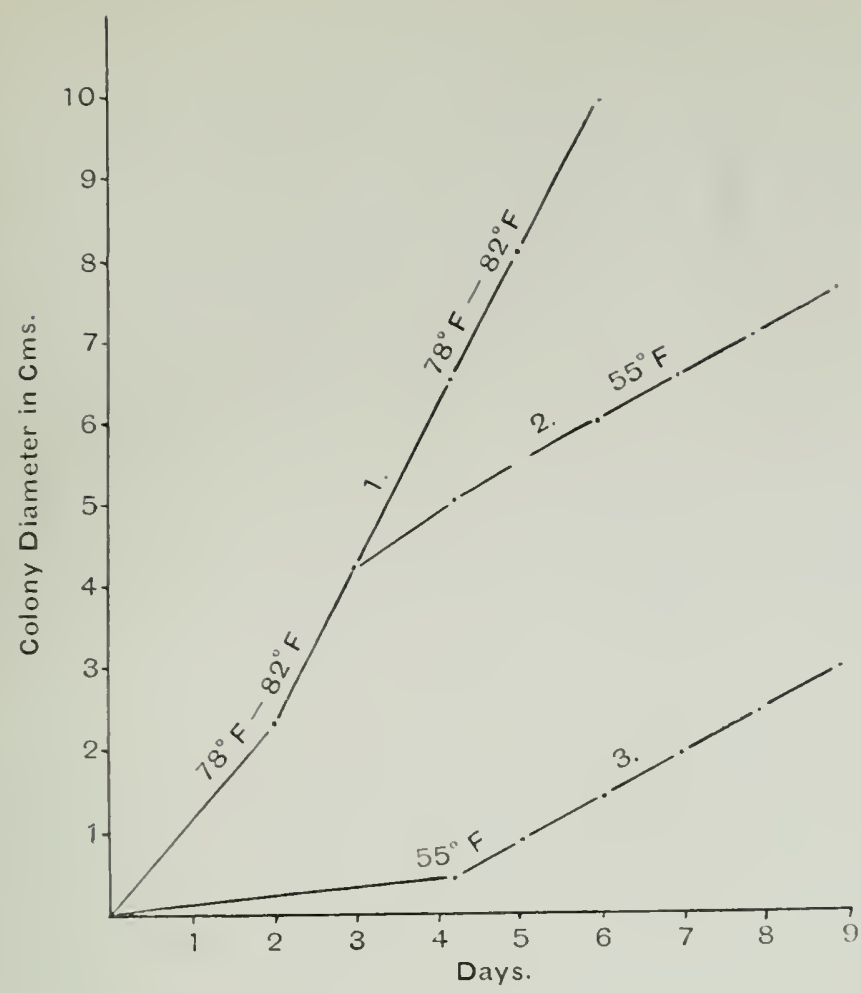

Fig. 27.-Growth Curves for Gloeosporium musarum at $78-82 \mathrm{~F}$. and $55 \mathrm{~F}$. (see text).

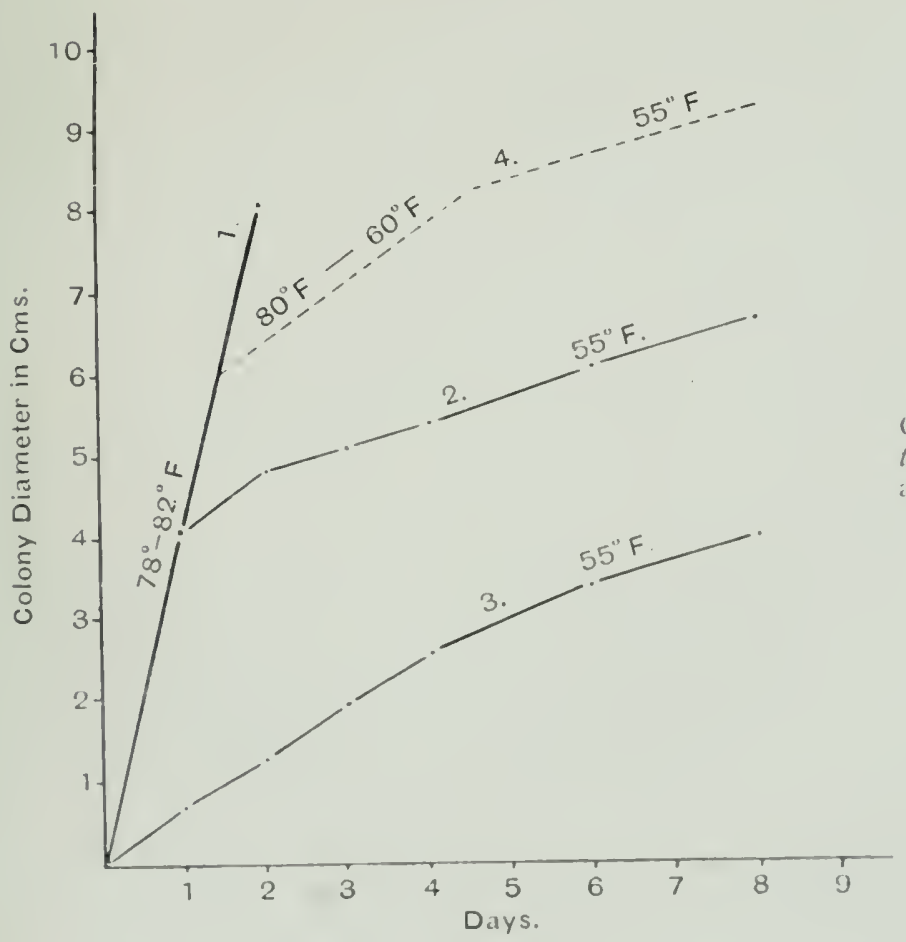

Fig. 2 s. - (irow 1 th

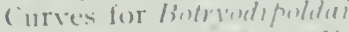

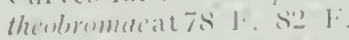

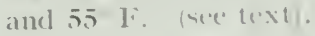


characteristic growth rate for this temperature. The very different growths achieved under the three conditions is evident from the graph. Thus we find that while at room temperature $\left(78^{\circ} \mathrm{F} .-82^{\circ} \mathrm{F}\right.$.) a growth of $10 \mathrm{cms}$. is achieved in six days, by extending Curves 2 and 3 , the same amount of growth is not achieved until the end of fourteen and twenty-three days respectively. In Fig. 28 similar curves are shown for Botryodiplodia, which, in contrast to Gloeosporium, is a rapidly growing organism. Here again the effect of temperature is most striking. Curve 4 gives a theoretical conception of the behariour of this fungus on Colombian fruit, from the time of reaping to the stabilising of flesh temperatures at $53^{\circ} \mathrm{F}$. The important point is that infection becomes thoroughly established at the higher temperatures, and is in marked contrast to the extent of infection when the fruit is quickly brought to the lower temperature.

\section{Determination of Carbon Dioxide Concentration.}

In view of the temperatures found, samples of air were taken from various parts of the holds, and later analysed by means of the Haldane Apparatus. The air of the holds is completely blown out twice daily, namely, at $6 \mathrm{a} . \mathrm{m}$. and $6 \mathrm{p} . \mathrm{m}$., and it is interesting to note that in samples taken at 2.30 p.m. the carbon dioxide concentrations ranged from 0.05 per cent. to 0.3 per cent. ; in two isolated cases, 0.5 per cent. and 0.48 per cent. were recorded. These are indeed low, and, considered in the light of the self-heating of fruit in bulk $(90,000$ odd bunches), with consequent acceleration of respiration, must be regarded as a tribute to the efficiency of the fans and ventilation system of the banana boats.

\section{I'I. Recommendations regarding Main Stalk Rot.}

There seems little doubt that the financial losses attendant on main-stalk rot will be very considerably reduced by :-

(1) Cutting stalks long-about 10 inches-when reaping bunches (vide (2) below).

(2) The application of the vaseline treatment. We recommend that when a bunch has been passed for shipment after final inspection at the quayside the stem ends be freshly cut with a sharp instrument and throughly vaselined. In this way the fungal organisms which have become established in the long interval between reaping and loading will be eliminated. 
(3) Commencing refrigeration as soon as possible after loading. As soon as a deck has been loaded it should be sealed up by means of efficient baffles, the air thoroughly blown out, and refrigeration commenced without further delay. (The arrangement of the air trunks on some boats may be such that this procedure would involve waste of refrigeration, but the improved state of the cargo on arrival overseas should compensate adequately.)

(4) Rapid cooling of the cargoes. It should be the aim of the boats' refrigeration staff that, within twelve hours at the most, the fans deliver cold air at $53^{\circ} \mathrm{F}$. Under similar conditions, no chilling effects were recorded in our transport trials.

\section{Paper Bag Experiments.}

The use of crates, containers, blanketing, etc., has been repeatedly resorted to in the export of varieties which experiment had shown to be unsuited to transport under the customary Gros Michel conditions of treatment. It will be readily conceded that with a variety like the Gros Michel, which is not so predisposed to bruising, the use of an envelope of smooth brown paper makes possible the transport, and arrival at destination, of fruit with the absolute minimum of bruises, scratches, etc. On ripening to its characteristic rich colour, the resulting product is of surprisingly attractive appearance. Several points, however, call for comment.

While these bags are not intended to be airtight, haring a hole at the bottom through which the lower end of the stalk passes, and being tied up with string at the other end, they nevertheless offer serious resistance to the passage of cold air through them, with consequent interference to :-

(1) The cooling down of the fruit inside them. The relation between main-stalk rot and temperature has been discussed fully above.

(2) The removal of the volatile products emanating from the fruit.

In short, the use of such bags affects very materially two important inter-dependent rariables of the storage chamber, namely, temperature and composition of the atmosphere. Actual measurements showed that while the ordinary air temperature of the holds was $6(1) \cdot \mathrm{S}^{\circ} \mathrm{F}$., the average air temperature within the bags was 
$67 \cdot 4^{\circ} \mathrm{F}$.-nearly $7^{\circ} \mathrm{F}$. higher. These observations were made in bags as far removed from the margin as one could conveniently reach without unduly disturbing the cargo. But what conditions obtain in the centre of the pack!

This difference is considerable, and in the longer voyages, particularly when the boat is appreciably delayed through inclement weather, may be attendant with serious consequences, since the higher temperature of itself would make for conditions of more rapid maturation in terms of Van 't Hoff's law, applied to biological reactions. Support is lent to the view by Olney*, who showed that at a temperature of $53.6^{\circ} \mathrm{F}$. respiration in the banana proceeded at one-third of the rate at $68^{\circ} \mathrm{F}$., and by Kidd and West, $\uparrow$ who point out the undoubted correlation between activity of respiration and length of storage life. It would, therefore, be interesting to know at what rate these bunches are cooled, as judged by flesh temperatures. In stored apples, the presence of high concentrations of carbon dioxide is responsible for the incidence of a functional or non-parasitic disease, known as Brown Heart. Light will be thrown on the question of inimical concentrations in the course of work in progress on the behaviour of the banana in atmospheres of varying partial pressures of carbon dioxide and oxygen at different temperatures.

It was thought that a simple modification $\S$ might accrue to advantage. Accordingly, 36 bags were punched with holes, $\frac{3}{8}$ inch diameter, set 4 inches apart. These holes would, of course, tend to weaken the bags, especially in the case of fruit bagged in a surfacewet condition, but doubtless this objection might be over-ruled by the choice of paper of suitably resistant texture. The behaviour in storage and ripening of representative fruit in bags with and without holes was compared. The superiority of the former was clearly demonstrated :

(1) While over 60 per cent. of the bunches in the unpunched bags showed acute main-stalk rot, there was an incidence of 6 per cent. only in the corresponding punched set.

* Olney, A. J. : The Temperature and Respiration of Ripening Bananas. Bot. Gaz., 1929. Hull Botanical Laboratory, 361.

† Kidd. F., and West, C. : Food Invest. Board. Ann. Report, 1927.

\# "Brown Heart": A Functional Disease of Apples and Pears. Food Invest. Board, Special Report No. 12, 1923. Kidd, F., and West, C.

S We have learnt through London correspondence of 11th April, 1930, that the

itish Banana Company (Vestey) have found the use of bags with holes of 1 inch eter an improvement.

$5+$ 
(2) Cooling in the former was more rapid; during the first twenty-four hours of storage, the average difference between the air temperatures within the bags, punched and unpunched, ranged consistently between $2^{\circ} \mathrm{F}$. and $2 \cdot 3^{\circ} \mathrm{F}$. These figures are significant, when the rate of cooling of our small consignments is realised, and enables one to form some impression of the magnitude of improvement possible in a large cargo of 30,000 bagged bunches or more, especially as the chief object of the bagging process - the prevention of bruising - was not perceptibly defeated by the presence of these small holes.

\section{CRATED FRUIT.}

The carriage of some fruit in the East to certain Australian markets is done in crates, the bunches being cut up into hands before being crated. In anticipation of inquiries from British Colonies interested in this trade, the question of crated bananas has been given a good deal of attention.

The main difficulty encountered is the tendency to unerenness of ripening within the crates, coupled with the fact that the fruit tends to ripen comparatively more quickly when cut into hands than when left in the bunch. For example, the breaking of the stem towards the lower part of the bunch has frequently been observed to cause premature ripening in the lower hands.

Unerenness of ripening may be attributed :

(1) To uneven temperature within the crates.

(2) To the crating together of fruit of different stages of maturity at time of harvesting.

(3) To the fact that the normal ripening of a bunch proceeds progressively from the top, or first formed hand, downwards towards the lowermost, and thus, under similar conditions, one would expect different rates of ripening in the different hands of the same bunch, provided, of course, that the temperature wats not sufficiently low to inhibit the natural functioning of the ripening enzyme (or enzymes).

(4) To the incidence of fungal diseases.

Our experiments with crated fruit may be divided into three series :-

(1) The earlier experiments were undertaken to confirm the advisability of cutting the bunches by a transierse cut through the main stem above each hand, leaving a cylinder of about 
1 inch of main stalk to each hand, as opposed to cutting off the hands by a longitudinal cut through the cushion or emergence of a hand. The former method proved superior, the fruit being of a decidedly better flavour.

(2) In the next series of experiments, as soon as the fruit had been loaded into the Cold Chamber held at $53^{\circ} \mathrm{F}$., it was promptly cut into hands, and half of this bulk was immediately packed in crates, with the usual wrapping of banana trash, etc. The other half was left in the same chamber for approximately forty-eight hours, together with empty crates and trash, until the flesh temperature of the fruit had been reduced to $53^{\circ} \mathrm{F}$., and was then crated. In other words, this series of experiments may be described as warm fruit packed with warm material versus pre-cooled fruit packed with cooled material. The advantage of pre-cooling was clearly evident in (i) evenness of temperature within the crates, (ii) the fruit remaining green and firm for the period representing transport in cool storage. In both cases, however, there was a considerable amount of infection with Glocosporium and typical main-stalk rot, which, in many cases, particularly with the warm fruit, had progressed through the cushions into the individual finger-stalks. Early finger-dropping would make this consignment difficult, if not impossible, to handle, quite apart from the unattractiveness of its appearance.

(3) With a view to improving these conditions, the third series of experiments was commenced to test the advisability of cutting into hands before or after cooling down to $53^{\circ} \mathrm{F}$. As soon as the fruit had been loaded into the cold chamber, it was divided into two representative lots, one of which was immediately cut into hands. After forty-eight hours, when flesh temperatures of both stalk and individual fruits had been reduced to approximately $53^{\circ} \mathrm{F}$., these hands were crated as in the preceding series. At the same time, the bunches which had been left whole were then cut up into hands and crated forthwith. In both sets cooled packing material was used. The latter set, which had been cooled prior to being cut into hands, was remarkably superior (see Fig. 29). While there was a considerable amount of typical main-stalk rot, fungal penetration had, in no observed instance, passed into the cushion, with the result that the consignment was ripened in the course of a few days, and from the trade point of view, could be handled without the slightest inconvenience. 


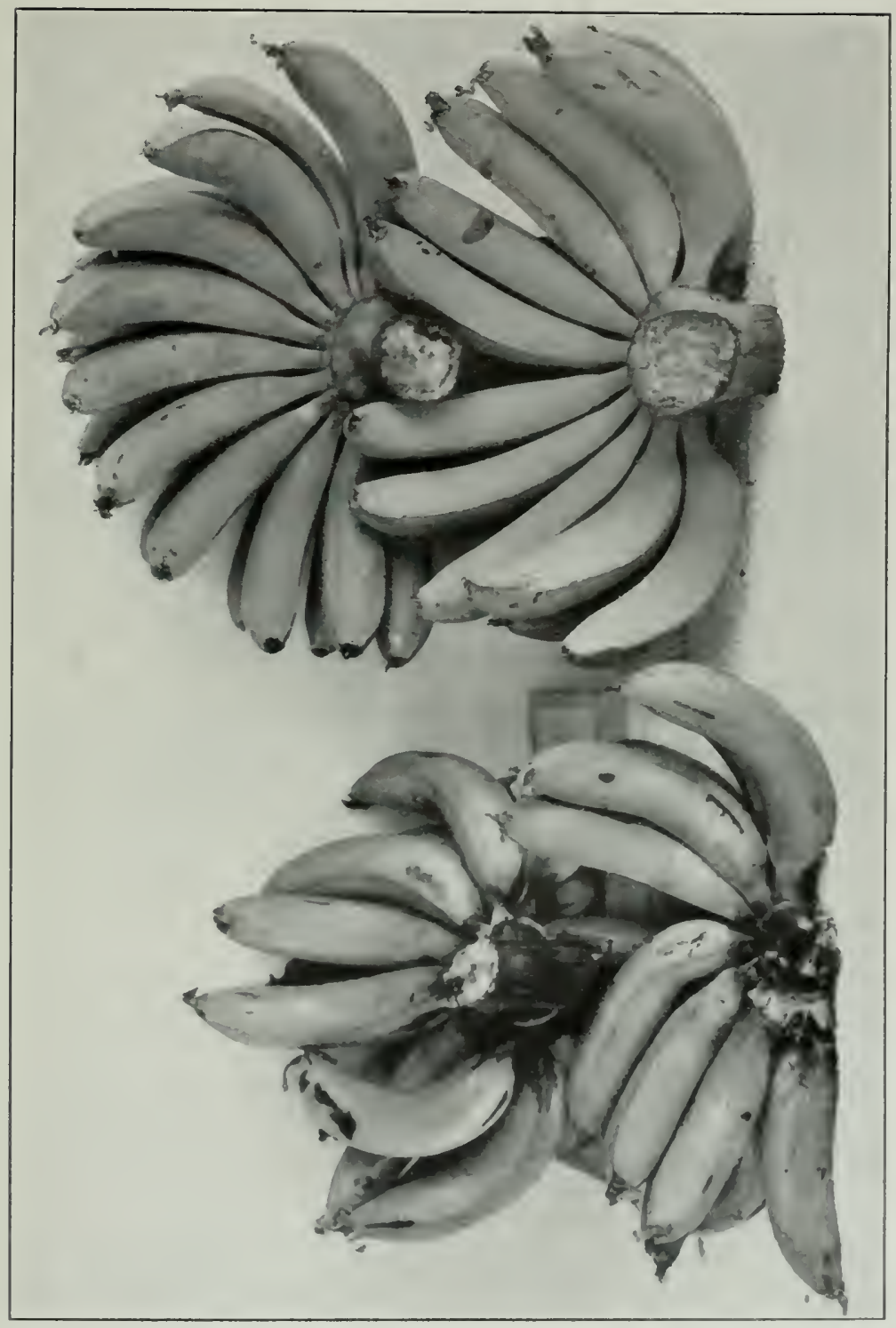

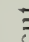

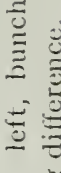

-

I

है क

こ

蔦

$\stackrel{20}{=}$

芯

$\leq \cong$

$\Xi \equiv$

등

$\equiv \equiv$

$\Xi$

כ

气

$\stackrel{1}{5}$

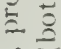

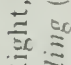

$\simeq \cong$

$\stackrel{3}{3}$

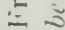

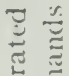

t)

เ $\stackrel{3}{\Xi}$

$\therefore$

$=$ 
To the best of our knowledge, such pre-cooling of the whole bunch has not hitherto been attempted as part of routine procedure -its adoption should very materially benefit the crated industry.

This pre-cooling of the whole bunch serves a further useful purpose in the case of fruit in a surface-wet condition. This condition is not of itself harmful. As a matter of ordinary procedure, bananas transported in the " naked" condition are subjected to the drying action of rapidly circulating air shortly after loading; in the case, however, of fruit crated in a surface-wet condition without pre-cooling, the matter is rery different. High temperatures, which are often the rule towards the centre of the cargo stack, in conjunction with the high humidity introduced by wet fruit, favour the growth of rot organisms so often responsible for the considerable wastage in, and unsightly appearance of, banana cargoes.

In conclusion, our investigation of the storage behaviour of the banana crated in hands, emphasises strongly the necessity for :--

(1) Careful selection of fruit at the correct stage of maturity. (This will be governed chiefly by the length of royage.)

(2) Shortening as much as possible the interval between reaping and transference to the cool storage chamber.

(3) Thorough pre-cooling of the whole bunch prior to cutting into hands. For journeys of ten days or longer, the vaseline treatment is strongly recommended.

(4) Rapid transference, in insulated conveyers if necessary, from the pre-cooling station into the ship's hold.

(5) The maintenance of a temperature of $53^{\circ} \mathrm{F},-55^{\circ} \mathrm{F}$. in the case of Carendish and Gros Michel.

(6) The complete change of the storage atmosphere at least once (preferably twice with large consignments) per day.

(7) The use of "dunnage" on crates, and the provision of vertical breaks in the cargo stacks, when these are large.

\section{CONCLLDING OBSERVATIONS.}

1. The behaviour in storage, and during ripening, of a number of immune varieties, as a possible substitute for the Gros Michel, was studied. The Lacatan and the Cavendish alone seemed promising, judged by commercial criteria. 
2. The Cavendish variety, in the course of bulk storage trials, gave promising results. If these are confirmed in later storage trials, the West Indian Cavendish, as exemplified by good Trinidad fruit, seems a suitable substitute for the Gros Michel.

3. Main-stalk Rot has been shown to be due to a plurality of organisms. The more important of these have been isolated in pure culture, identified, and their growth rates at different temperatures and their pathogenicity demonstrated.

4. Definite measures for the prevention of Main-stalk Rot have been put forward.

5. With regard to the transport of bananas in paper wrappers, perforated bags have been shown to allow of more rapid cooling and more efficient ventilation.

6. Measures for the reduction of wastage in, and the improvement of, crated cargoes of bananas, have been submitted. The importance of pre-cooling the bunch before cutting into hands cannot be emphasised too strongly. 


\section{APPENDIX.}

\section{BANANA FRUIT DISEASES.*}

A review of the literature on fungal diseases of banana fruits by C. W. WARDLAw, Ph.D., D.Sc., F.R.S.E.,

Banana Pathologist, Imperial College of Tropical Agriculture.

[This brief review of the literature on fungal diseases of banana fruits is preliminary to work on this subject which is being carricd out at the Low Temperature Research Station of the Imperial College of Tropical Agriculture, Trinidad.]

\section{INTRODUCTION.}

The literature on this subject is relatively inextensive. A number of fungal organisms are involved, some of which have a wide geographical range. Significant parasitism may take place in the field or disease may only make its appearance on fruit during storage or transport. In this brief review an attempt has been made to give an account of the principal fungi involved in producing diseases of banana fruit, to indicate the salient features of their attacks, and, where information is arailable, the conditions under which they reach their maximum importance.

The organisms which have been reported in relation to fruit-stem and finger disease include :-

1. Glocosporium musarum, Cooke and Massee.

2. Cercospora musarum, Ashby.

3. Macrophoma musae, Cke, Berl and Vogl.

4. I'erticillium sp.

5. Thielairopsis paradoxa, Ion Hohnel.

6. Fusarium spp.

\section{STEII-END ROT.}

Before proceeding to an account of the individual fungi which have been investigated in detail, some reference must first of all be made to the general storage disease known as "Stem-end Rot." Simmonds' account ${ }^{22}$ is characteristic, and may be quoted at length.

"This disease is sometimes known as Black End owing to the fact that affected fruit exhibit a black area of soft rot round the stem-end.

"Symptoms. - The trouble usually commences as a dark water-soaked area formed in connection with a bruise or other injury to the short fruit stalk or working in from its broken end. As the rot progresses the stalk turns completely black, and becomes much shrunken and sometimes shredded. From the stalk the soft blackened area extends through the skin of the fruit at a more or less rapid rate, the pulp beneath turning soft and watery.

"Stem-end Rot is not a disease of the plantation as it usually appears only when the fruit are approaching maturity, especially after long distance consignment.

* Reprinted by permission from "Tropical Agriculture," Vol. VII, No. 5, pp. 115-119. 60 
"Cause.-Associated with this rot are usually to be found fungi of the genera Terticillium, Glocosporium and Fusurium. It would appear that under suitable conditions any weak wound parasite of this type would be capable of producing similar injury. Careful examination of affected fruit will reveal the fact that the primary cause of the trouble lies in injuries given to the fruit during the frequent handling to which it is subject. The injury may be due to bending the fruit stalks while the hand is still on the bunch. The bruise resulting from this is sufficient to constitute a point of entry for the rot-producing fungi without a definite abrasion of the skin. The wounds and bruises arising from tearing apart the fingers from the hand will also serve as infection points. These latter are a common source of trouble in cased fruit.

"Control.-(1) As regards fruit marketed in the bunch it is essential that the bunches receive most careful handling from the time they are cut until they reach the consumer. When one considers the rough treatment the fruit is often subjected to it is remarkable that not more damage results.

(2) In order to lessen Stem-end Rot in cased fruit it will be necessary to pack in hands or half-hands rather than in singles. The hands should be carefully cut off round the collar by which they are attached to the central stalk, and if it is necessary to reduce them in size the division should be made by a sharp knife and not by a tearing process.

(3) The grower should avoid accumulating a heap of rotting banana refuse round his packing shed. This material serves as a breeding ground for the various organisms causing Stem-end Rot, and spores produced here may serve to contaminate fruit during the process of packing. The discarded fruit and stalks could be thrown into a pit, and covered now and then with a layer of soil.

(4) The same need for cleanliness may be stressed with regard to some ripening rooms. The absence of a regular cleansing programme will increase the chance of infection with rot fungi."

It should be stated here that the term Stem-end Rot leads to confusion as different diseases are implied by different workers. Thus while Simmonds uses it to denote a disease of the finger stem, the same name is also used to indicate an important downward rotting of the main stem of the whole bunch in the case of fruit transported for the English Market.

\section{GLOEOSPORILM MLSARLM, COOK AND MASSEL.}

This fungus, found in all parts of the world where bananas are grown, canses a fruit disease known as Banana Anthracnose, black rot, or ripe fruit rot. Fruit may be affected in the field, in the local markets or during large scale transport. The most important researches are those of Agati ${ }^{2}$ in the Philippines, and Toro ${ }^{23}$ in Porto Rico.

Vature of the Disease.

(a) In the Field. - The most active form of anthracnose appears to be that described by Agati in the Philippines where the fungus behaves as a parasite on green fruit in the field as well as on mature fruit in storage. There, as many as 16 per cent of the bunches may be affected. Early stages of infection are recognised by the appearance of small black circular specks on the flowers, skin, and distal ends of the lands. These spots increase in size, anrl as the disease reaches an advanced stage they become 
surken and coalesce, forming larger spots. When infection is severe the whole fruit is entirely covered with such dark blemishes. On the surface of the latter characteristic bright salmon-coloured groups of moist spores appear. Infected fruits ripen prematurely; and finally turn black and rotten.

(b) In Storage.-While in some countries G. musarum can definitely behave as a parasite in the field, most of the published work refers to its activity on fruit which has been reaped and stored. Thus in Toro's account the damage caused by the fungus is restricted to reaped fruit which was being used for local markets or for export. Toro states that the first manifestations of the disease appear with the ripening of the fruit after cutting. His general description is in agreement with that of Agati, except that different degrees of infection are shown by different varieties. The final result consists in a blackening of the stem and skin, and the appearance of bright-coloured moist spore masses, while the flesh within is softened, bitter to taste and finally rotted.

\section{Conditions of Infection.}

The factors which make for significant infection by G. musarum include (i) atmospheric humidity and temperature, (ii) presence of bruises or injuries, (iii) state of maturity of the fruit, and (iv) resistance or susceptibility of the banana variety under observation. Agati showed by the use of spore traps that the spores of G. musarum are abundantly dispersed by wind. They may also be carried by the numerous insects which frequent banana fruits. The spores germinate freely in water, but are quickly affected by drought. The state of atmospheric humidity is thus of fundamental importance in determining the extent of infection. Agat found that his experimental inoculations developed most rapidly during rainy days, and also that under these conditions field infections were most prevalent. He also found that fruit stored in damp places was easily affected, especially when bruised in any way. The amount of disease on stored fruit was directly correlated with the degree of maturity, notably where the sweeter varieties were involved, and where fruit had been bruised in handling. On this subject it has been stated by Delacroix ${ }^{-10}$ and others that G. musarum is a wound parasite, and that it can only cause anthracnose when fruits have been injured. Toro's inoculation experiments showed that the fungus cannot enter uninjured green or partly matured fruit in the field even of the most susceptible varities. On the other hand, completely matured bananas, when placed under proper conditions, became diseased whether injured or not. This observation has been correlated with important changes in the chemical and physical constitution of the peel. These include an increase in the sugar content accompanied by a softening of tissue. Toro also demonstrated that the mycelium of $G$. musarum secretes an enzyme which though capable of dissolving the parenchymatous tissue of mature fruit, has no apparent effect on unripened bananas or on the epidermal tissue of either immature or mature fruit. He postulates mechanical injury, accompanied by softening of the peel and increase in sugar content as being important conditions for infection.

\section{Tarielal Susceptibility.}

Agati found that 30 different varieties under observation all showed some degree of infection by G. musarum. The greatest amount was found in the sweet varieties, including the Lacatan, Bongolan, and Cavendish. The less sweet fruits were not so subject to attack. He divided his fruits into two classes-(1) those readily infected and (2) those less readily infected. The former required six to ten days for infection, the latter 15 to 23 days. All varieties, however, finally showed that some fungal 
penetration had taken place. Toro confirms Agati's observation that the sweeter varieties are more susceptible, and quotes the Dwarf or Canary banana (.M. cavendishii) as being the most susceptible. Plantain varieties (Musa paradisiaca) showed a greater degree of resistance. Toro attempted to link up the question of resistance with the tannin content of the peel. His observations, however, gave a negative result, from which he concludes that resistance and susceptibility are correlated with anatomical characters.

Strains of the organism.

From the accounts given by Agati ${ }^{2}{ }^{2}$, Toro ${ }^{23}$ and others it is evident that G. musurum exists as a number of different strains with a wide range in relative pathogenicity. On the other hand, the difference in power of infection may be referable to some extent to different climatic and growth conditions, but further work is required before a definite conclusion can be given. Laubert ${ }^{14}$ has stated that anthracnose is prevalent in consignments of bananas supplied to the German market from Jamaica and elsewhere. In 1910 he expressed the view that the causal organism was a distinct biological form, and proposed the name G. musarum var importutum; subsequently it has been suggested that the organism in question is identical with or very closely. related to $G$. fructigenum, f. Americana.

\section{Preventive Measures.}

The general treatment for anthracnose is similar to that prescribed by Simmonds 22 for Stem-end Rot. Agati's recommendations, based on the physiological behaviour of the parasite, include the following :- Storage fruit should be kept in well rentilated rooms ; fruit should be carefully handled at the time of reaping to avoid bruising : bruised fruit should never be stored with sound frnit ; fruit stems should be cut with a sharp implement, and not too close to the fruit ; store-rooms should be thoroughly cleaned before storing the fruit; fruit that is attacked first should be immediately separated from sound fruit to check the further spread of the disease; spraying diseased fruit with Burgundy mixture is beneficial; sirce immature fruit takes a longer time to ripen and hence may be attacked by the fungus before it is ripe, fruit should never be harvested until it is mature. While Agati's recommendations may be found applicable to small quantities of fruit not all of these pracautionary measures can be utilised where large consignments are being handled. Toro on the other hand, states that no preventive neasures can be practised advantageously, except the aeration of the "hands" in the bunches to allow of ventilation, recluce moisture and insure proper temperature.

\section{HELMINTHOSPORILM TORLLOSLM, SYD. ASHBY, COMB. NOV. (CERCOSPORA IIUSARCM, ASHBY.)}

This organism, originally described by $\mathrm{Ashby}{ }^{4}$ as the fungus of " blackspot disease " on the leaves of the Gros Michel banana, has recently been shown by Ogilvie ${ }^{16}$ to be the canse of an important clisease of the Dwarf, Canary, or Cavindish banana (Musa cavendishii) in Bermuda known as "Black Tip." Ashby also mentions that young fruit may be badly spotted, but no rotting ensues. This organism may also be found to be the canse of a finger tip rot described from Jamaica ${ }^{3}$.

Occurrence and Symptoms.

Under certain conditions a black discolouration becomes apparent just below the flower and progresses down the fruit, so that in three wecks' time 2 inches may have become affected. Diseased areas are frequently irregular in outline; they are 
bordered by a narrow grey or light yellow margin, and frequently affect one side of the fruit more strongly than the other. The activity of the causal organism, H. torulosum (C. musarmm), was frequently obscured by the presence of other fungi, including species of Fusarium, Aspergillus luchuensis, Glocosporium musarum, and species of Macrosporium, Alternaria and Cephalosporium. Various insects were also frequently found in association with diseased fruit. Inoculation experiments, both on bunches in the field and on detached fruit in the laboratory, indicated conclusively that Cercospora musarum was the only definite parasite involved. This organism produced a rapid discolouration when placed in small incisions in the skin of green bananas, and in about three weeks a lesion some 2 inches long was produced. The whole fruit is seldom affected, and ripening appears to inhibit the further development of the lesion. At this stage, however, the affected area tends to split, and the numerous insects thereby attracted soon render the fruit unsaleable.

\section{Influence of External Conditions.}

Ogilvie states that the disease is most noticeable on both fruits and leaves during the summer months in Bermuda (late June, July, August and September), when the mean maximum temperature is above $75^{\circ} \mathrm{F}$. By the beginning of October, on the other hand, there is comparatively little discolouration of the tips of the very young fruits.

\section{Control Measures.}

Cercospora musarum in Bermuda is thus a definite parasite on young fruit under field conditions, high temperature being an important predisposing factor. Control measures are based on ameliorated plantation sanitation, since it has been found that greatest loss occurs in old, closely planted, and badly drained fields. It is recommended that diseased fruit, trash, and large leaf infections should be removed.

\section{MACROPHOMA MLSAE, CKE, BERL. AND VOGL. (PHOMA ILSAE, CARPENTER.)}

This organism gives rise to "Freckle " or " Black Spot " disease of the banana and plantain. It has been reported by Carpenter ${ }^{8}$ from Hawaii, by Campbell ${ }^{6}$ from Fiji, and by Reinking ${ }^{20},{ }^{21}$, Ocfemia ${ }^{17}$ and Lee ${ }^{15}$ from the Philippine Islands.

\section{Symptoms.}

Lee states that green and mature banana fruits in public markets in the Philippines are commonly spotted with reddish-brown to black spots, on which pycnidia appear. The disease is of long standing, and occurs on practically all of the commercially important varieties of Musa sapientum. It does not seem to cause much damage, since the fungus rarely penetrates deeper than the rind of the fruit. Ocfemia states that the spots are much more abundant on the upper than on the lower surface of the leaves. The upper exposed parts of the fruit may be entirely covered with the freckles so as to have a blackish appearance. The black spots are surrounded by a narrow band of more or less water-soaked tissue. In Hawaii Carpenter states that the disease has spread rapidly, and is a serious pest in practically all the plantations of the Chinese or Dwarf banana (1918). The bunches of fruit from badly affected plants are undersized, discoloured, unevenly ripened, and unsuitable for export. Undersized fruit as well as undeveloped bunches may have to be cut prematurely the result of disease. While the flesh may be unimpaired the extensive surface lemishing renders the fruit unsightly and unsuitable for export. 
Conditions affecting the Disease.

Ocfemia states that under field conditions the spread of the disease appears to be effected by rain-water, secondary lesions being produced only on portions of the fruit and leaves washed by conidia-laden rain-water. According to Lee the disease is much more abundant at the close of the wet than during the dry season.

\section{Varietal Susceptibility.}

Reinking ${ }^{21}$ states that while conducting an investigation in Hawaii it was observed that the Gros Michel banana of Central America appeared to be resistant to the disease, as no infection was noted on this variety even when growing adjacent to heavily infected bananas of the Chinese or Dwarf variety. The so-callecl recl variety of Saba (Sabang Pula), in the Philippines, is severely affected on both leaves and fruit.

\section{Control.}

According to Carpenter no satisfactory method of controlling this organism has yet been established, other than general sanitation and leaf spraying with Borcleaux mixture to keep down infection until the bunch appears and matures.

\section{VERTICILLILM SP.}

Dade ${ }^{9}$, reporting on banana diseases from the Gold Coast, has described a fing( 1 tip rot of the Canary Banana (M/usa cevendishii) associated witlı a species of I'crticillium (Stacliylidium) which he considers as probably identical with a similar disease reported from the Canary Istands. Bensuade ${ }^{5}$ also states that in $\$$. Miguel, Azores, bananis are seriously affected by a disease attributed to a species of slachlidium. A similar disease generally described as "Cigar End" is known in l'anama, and in the Canary Islands and Madeira. The organism has also been described by Simmonde22 in connection with Stem-end Rot, and "Cigar End" in Queensland. Darle's brief account is as follows. The dead flowers adhere persistently to the fruit and a very imperfect cork layer is formed. Infection takes place by this path, after the preliminary infection, blackening and withering of the perianth have oecurred. Rotting may proceed over one-third of the length of the fruit. Rhizopus mgricuns, a sapherophytic mould follows the rot. Simmonds states that " (igar End" is a disease to which the fruits are subject in their more immature stages. Commonly, only a few of the fingers of the bunch exhibit the simptoms although sometimes the whote bunch is affected. His description is as follow's:

"Affected fruit exhibit a firm black rot at the apex. The extent of the decay varies from a scarcely noticeable ring of black tissue romel the terminal crown to at regular extension back for hatf an inch or more. The affected portion shrinks, in many cases becoming more or less roundeel in contrast to the angular shalpe of the immature fruit. The blackeneel tissue then becomes covered from the elistal end back with an ashy grey or sometimes pinkish-giey coat of fungal spores, which give, in typical cases, the striking resemblance to a burnt cigall tip to which the disease owes its name. The old shrivelled flowal organs often persist for considerably lenger than the normal period on affected fruit.

"A fungus (I'erticillium sp.) is almost universally associated with " ("igall End, " and it is the conicliospores and spores of this organism closely studeled orer the affected region which give rise to the grey covering characteristic if the disease. A comsiclerattion of the early stages of attack would suggest that infection maly presilhly take plater through the tender floral structures which appear particularly susceptible to fungus invasion." 
Control.

In the Canaries the disease causes much trouble, and requires expensive hand control, namely, the removal of pistil and perianth as soon as the fruit begins to form. Simmonds suggests that the young bunches should be opened up to the light and air and the bracts, which sometimes tend to remain attached to the developing hand, especially during wet weather, be removed as soon as possible.

\section{THIELAVIOPSIS PARADONA, VON HOHNEL.}

Roldan ${ }^{18}$ showed by experimental inoculation that this organism was capable of attacking banana fruit, while more recently Hansford ${ }^{12}$ has reported it as causing a rot of clamaged banana fruit in Uganda.

\section{FLSARIUM SPP.}

So far as the writer is aware no species of Fusarium have been found to be directly parasitic on uninjured immature or maturing banana fruits. On the other hand, they appear to be of frequent occurrence after preliminary infections by parasitic organisms have taken place. As disease tends to be extended and intensified by such saprophytic activity reference may be made to some of the species of Fusarium involved. Thus Ogilvie $^{16}$ found that the blackened tips of bananas which had been attacked by Cercospora musarum in moist weather frequently became covered by a growth of Fusarium. The latter was frequently tound associated with withering flowers, while advanced stages of the Cercospora infection were frequently obscured by thick growths of Fusarium, Cephalosporium and other fungi. Campbell ${ }^{6}$ in Fiji, mentions a condition possibly identical with "Black End" on bananas kept in the laboratory. Beginning at the upper part of the bunch the fingers become blackened and constricted at the stalk end, and finally fall at a touch. A species of Fusarium which appears to be constantly associated with the disease was isolated and is suspected, but not yet definitely known, to be the cause of the trouble. Reinking and Wollenweber ${ }^{19}$ have also given an account of Fusarium species associated with fruit diseases. Thus they found $F$. pusillum on sun-burned Congo fruit, $F$. semitectum on dead floral parts at the ends of banana fruits, and on diseased fruits, F. camploceras on rotted fruit, $F$. bullatum on clead floral parts at the tip of the fruit, F. moniliforme in the interior of diseased pseudo-stems, and on dead floral parts, etc. Hansford ${ }^{13}$ has recorded similar isolations from Jamaica. 


\section{BIBLIOGRAPHY.}

1. Agati, J. A.-Banana Stem and Fruit Rot. Philippine .1griculturist, 1922.

2. Agati, J. A.-The Anthracnose of Abaca, or Manila Hemp. Philippine Agriculturist, Vol. XIII, 1925.

3. Anon.-The Banana and its cultivation with special reference to the British Empire. Bull. of the Imperia? Institute, Vol. XXII, 1924.

4. Ashby, S. F.-Banana Diseases in Jamaica. Bull. Dept. Agric. Jamaica, Vol. II, No. 6, 1912.

5. Bensuade, M.-Inventory of the diseases of Economic Plants in St. Michial. Revier of Applied Mycology, Vol. VI, 1927.

6. Campbell, J. G. C.-Banana Diseases in Vitilevia. Agric. Circ, Department of Agriculture, Fiji, V, 1925.

7. Campbell, J. G. C.-Ann. Rept., Fiji Department of Agriculture, for rear 19261927.

8. Carpenter, C. IV.-Banana Freckle or Black Spot Disease. Report of the Ha curii Agriculture Experimental Station, 1918.

9. Dade, H. A.-Ann. Rept., Agricultural Department, Gold Coast, for 1925-1926.

10. Delacroix, G. O.-Sur le mode de developement du Champignon du Noir de: Bananes. Bull. de la Soc. Mycol. de France. XVill.

11. Dickson, B. T.-Leaf Spot of Bananas in Sonthern (2ueensland. Qurenslund Agric. Journ., XXX, 1928.

12. Hansford, C. G.- Amn. Rept., Uganda, Department of Agriculture for year encling 1927-1928.

13. Hansford, C. G.-The Fusaria of Jamaica. Kew Bull. Misc. Inf., 1926.

14. Laubert, R.-The Gloeosporium Rot of Bananas on the German .Iarket. Ruriti of Applied Mycology', V'ol. V'I, 1926.

15. Lee, H. A.-Banana Freckle in the Philippine Islands. Phytoputh, Vol. XII, 1922.

16. Ogilvie, L.- " Black Tip," a Iringer-tip disease of the Chinese Banana in Bermuli. Phytopath, XVII, 1928.

17. Ocfemia, G. O.-Macrophoma musae (Cke) Berl. and Vogl. and Phomat musite, Carpenter. Philippine Agriculturist, I'ol. XT', 1927.

18. Roldan, E. F.-The Soft Rot of Pineapple in the l'hilippine's and other countrie's. Philippine Agriculturist, Vol. XIII, 1925.

19. Reinking, O. A. and $\mathrm{H}$. W. Wollenwebber.- Tropical Fusaria. I'hilippini Journal of Science, Vol. 32, 1927.

20. Reinking, O. A.- Philippine Economic Plant Diseases. I'hitippinc Journal of Science, 1918.

21. Reinking, O. A.-- Banana Freckle and Leaf Spot. MYcologiu, XI'111, 1926.

22. Simmonds, J. H.-Diseases of the Banana in (pueenslanel. (michslund Africultural Journal, XXX, No. $5,1928$.

23. Toro, R. A.-Studies on Banana Anthracnuse. Joum. lipt. Isri., l'orto Rico, Vol. VI, 1922. 


\section{PUBLICATIONS OF THE EMPIRE MARKETING BOARD.}

E.M.B.1. Agricultural Economics in the EMPIRE. Report of a Committee appointed by the Empire Marketing Boart . . . . .

$6 d$.

E.M.B.2. Tropical Agricultural Research in the EMPIRE, with special reference to Cacao, Sugar Cane, Cotton and Palms. By C. A. Barber, Sc.D., C.I.E.

Reports on Development of Agriculture in Certain Colonies. By H. C. Sampson, C.I.E. :-

E.M.B.3. Trinidad

$$
\begin{array}{lllll} 
& \ldots & \ldots & \ldots & \ldots
\end{array}
$$

$3 d$.

E.M.B.4. British Guiana ..

$9 d$.

E.M.B.5. Leeward and Windward Islands and Barbados .. . . . . . . .

$6 d$.

E.M.B.6. Geophysical Surveying.

Report of a Sub-Committee of the Committee of Civil Research . . . . . . .

$6 d$.

E.M.B.7. The Chfmistry of Wine Making.

A Report on Oenological Research. By J. T. Hewitt, M.A., D.Sc., Ph.D., F.R.S. .

E.M.B.S. Grass aNd FONDER Crop CONSERVATION IN Traisportable Form. By A. N. Duckham, B.A., Dip. Agric. (Cantab.) .. .. 1s. 0 d.

E.M.B.9. Empire Marketing Board, May 1927 to

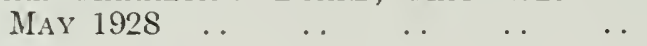

E.M.B.10. Empire Grown Sisal and its importance to the Cordage Manufacturer : Memorandum prepared by the Imperial Institute .. . .

$6 d$.

All prices are net; those in parentheses include postage.

Obtainable from the sale offices of HIS MAJESTY'S STATIONERY OFFICE 
Publications of the Empire Marketing Board-(continued).

E.M.B.11. Viticultural Research. Memorandum by $\begin{array}{lllll}\text { D. Akenhead, M.A., B.Sc. .. } & \text {.. } & \text {. } & \text { 1s. } 0 d \text {. (1s. 2d.) }\end{array}$

E.M.B.12. Report on INsect Infestation of Dried Fruir. By J. G. Myers, Sc.D., M.Sc., $\begin{array}{lllllllll}\text { F.E.S. } & \ldots & \ldots & \ldots & \ldots & \ldots & 1 s .0 d . & \text { (1s. } 2 d .)\end{array}$

E.M.B.13. Grape Fruit Culture in the West Indies and British Honduras. By Professor $\begin{array}{llllll}\text { H. Clark Powell, B.Sc. } & \ldots & \ldots & \text {. } & 1 s .0 d . \quad(1 s .2 d .)\end{array}$

E.M.B.14. Tile Survey Method of Research in Farm Economics. By J. P. Maxton, M.A., B.Sc.

$6 d$.

$(8 d)$

E.M.B.15. Oranges-World Production and Trade. Memorandum prepared in the Statistics and Intelligence Branch of the Empire $\begin{array}{lllllll}\text { Marketing Board } & \ldots & \ldots & \ldots & \ldots & 1 s, 0 d . & \text { (1s. 3d.) }\end{array}$

E.M.B.16. Report on Development of Agriculture in British Honduras. By H. C. Sampson, C.I.E. 1s. $6 d . \quad(1 s . \mathbf{S} d$.

E.M.B.17. Schistosomiasis and Malaria in Relation to Irrigation. By J. F. C. Haslam, M.C., M.D., M.R.C.P.Ed., D.P.H. $\quad$.. $\quad$.. $1 s .3 d . \quad$ (1s. $5 d$.)

E.M.B.18. The Composition of Pastures. By J. B. Orr, D.S.O., M.C., M.A., MI.D., D.Sc. . . . 9l. (11l.)

E.M.B.19. Empire Marketing Board, May 1928 to $\begin{array}{llllllll}\text { MaY } 1929 & \ldots & \ldots & \ldots & \ldots & \ldots & \text { 1s. } 0 d . \quad \text { (1s. 2 } d .)\end{array}$

E.M.B.20. Panania Disease of Bananas. Reports on Scientific Visits to the Banana Growing Countries of the IVest Indies, Central and South America. By Claude WV. Wardlaw, Ph.D., D.Sc., F.R.S.E., and Laurence P'. MIcGuire, Pli.D., M.Sc., D.I.C. $\quad . \quad \quad \ldots \quad$ 1s. 6il. (1s. 10i.) All prices are net; those in parentheses include postage.

Obtainable from the sale offices of

HIS MAJESTY'S STATIONERY OFFICE 


\section{Publications of the Empire Marketing Board-(continued).}

E.M.B.21. Wool-A Study of the Fibre. By S. G. Barker, Ph.D., D.I.C., F.Inst.P.,

M.I.Chem.F., F.R.S.E., F.Z.S. $\quad$. $\quad \ldots \quad 1 s .6 d . \quad(1 s .11 d$.

E.M.B.22. THE DEMAND FOR CHEESE IN LONDON. Report of an investigation into the Retail Marketing of Cheese in London by the Economic Section of the Empire Marketing Board

$1 s, 0 d . \quad(1 s .2 d$.

E.M.B.23. The Growing Dependence of British

INDUSTRY UPON EMPIRE MARKETS. By

F. L. McDougall, C.M.G., Representative of Australia on the Empire Marketing Board

1s. $0 d . \quad(1 s .1 d$.

E.M.B.24. Report on Insect Infestation of Stored Cacao. By J. IV. Munro, M.A., I).Sc., and W. S. Thomson, M.A. . $\quad \ldots \quad \ldots \quad 1 s .6 d . \quad$ (1s.8d.)

E.M.B.25. Indian (Suxy or Sann) Henrp. Its Production and Utilisation. Memorandum prepared $\begin{array}{llllll}\text { by the Imperial Institute } \ldots & \ldots & \ldots & 1 s .0 d . & \text { (1s. } 2 d .)\end{array}$

E.M.B.26. Britisil Industries and Empire Markets. By Professor A. J. Sargent, M.A... ․ 1s. $0 d$. (1s. 2d.)

E.M.P.27. CocoA: World Production and Trade. Memorandum prepared in the Statistics and Intelligence Branch of the Empire Marketing Board .. $\quad \ldots \quad \ldots \quad \ldots$ 1s. $0 d$. (1s. 3d.)

All prices are net; those in parentheses include postage.

Obtainable from the sale offices of HIS MAJESTY'S STATIONERY OFFICE 
Publications of the Empire Marketing Board-(continued).

E.M.B.28. Empire Marketing Board, May 1929 to $\begin{array}{lllllllll}\text { MAY } 1930 & \ldots & \ldots & \ldots & \ldots & \ldots & 1 \text { s. } 0 d . & (1 s, 2 \pi)\end{array}$

E.M.B.29. The Biological Control of Insect and Plant Pests. A Report on the Organisation and Progress of the Work of Farnham House Laboratory. By W. R. Thompson, Ph.D., D.Sc. .. $\quad \ldots \quad$.. 1 s. $0 d$. $\quad$ (1s. 4 d.)

E.M.B.30. Canadian Fruit Shipuients. Report of an Investigation by the Economic Section of the Empire Marketing Board into the Deterioration in Transit of Imported Canadian Fruit, 1927-1929 . . .

E.M.B.31. The Production of Tung Ohl in the Empire. Memorandum prepared by the Imperial

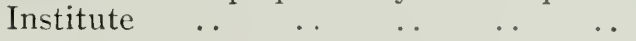
1s. 0d. (1s, 1d.)

E.M.B.32. Report on the Cultivation, Treathent and Prospects of Rice in British Guiana. By Charles E. Douglas, M.I.Mech.E., A.M.I.Pet.T., M.I.Struct.E. $\quad \ldots \quad \ldots \quad$ ls. $0 d . \quad(1 s .2 d$.

E.MI.B.33. The Dissemination of Researich Results AMoNg Agricultural Producers. Answers to a Questionnaire issued by the Empire Marketing Board, with an introduction by Sir A. Daniel Hall, K.C.B., F.R.S., LL.D.

E.M.B.34. The Demand for Empire Butter. Report of an Investigation by the Iiconomic Section of the Empire Narketing Board into the Retail Marketing of Butter in the

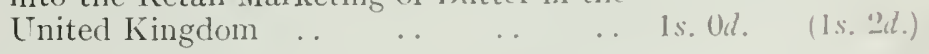

E.M.B.35. The Relative Values of (OA) 1 irerk ()ll.s from Varioes Solrees. By T'refesent J. C. I)rummond, 1).Sc., and I'Tufesin T. P. Hilditch, 1).Sc.

All prices are net; those in parcnetheses include postager. 


\section{REPORTS OF THE \\ IMPERIAL ECONOMIC COMMITTEE.}

\section{GENERAL.}

Eighth Report. The Functions and Work of the Imperial Economic Committee. (Cmd.3018). . 6d. (7d.)

Thirteenth Report. A Memorandum on the TRADE OF THE BRITISH EMPIRE: I 913 and 1925 to $\begin{array}{lllllll}1928 & \ldots & \ldots & \ldots & 6 d . & (7 d .)\end{array}$ Seventeenth Report. Procress Report .. . . 6d. ( $7 d$.)

TRADE SURVEYS.

Eleventh Report. A Survey of the Trade in Agricultural Machinery $6 d$. $\quad(8 d$.

Fourteenth Report. A Survey of the Trade in Rubber Manufactured Goods $\quad . \quad \ldots \quad \ldots 6 d$.

Ali prices are net; those in parentheses include postage.

Obtainable from the sale offices of

HIS MAJESTY'S STATIONERY OFFICE

LONDON: Adastral House, Kingsway, W.C.2. MANCHESTER : York Street.
EDINBURGH : 120, George Street.

CARDIFF : I, St. Andrew's Crescent.

BELFAST : 15, Donegall Square West.

Or through any Bookseller. 


\title{
REPORTS OF THE \\ IMPERIAL ECONOMIC COMMITTEE
}

\author{
on the Preparing for Market and Marketing \\ of Foodstuffs and Raw Materials produced \\ within the Empire.
}

Cmd. 2493. First Report. General _. . . $\quad 9 d . \quad$ (10d.)

Cmd. 2499. Second Report. Meat _. . . $\quad 9 d . \quad(10 d$.

Cmd. 265s. Third Report. Fruit .. .. 4s. 6d. (4s. 10d.)

Cmd. 2725. Fourth Report. Dairy Produce 1s. nd (1s. 2d.)

Cmd. 2934. Fifth Report. FISH N $\quad \ldots \quad 6 d . \quad$ (Sd.)

Cmd. 3015. Sixth and Seventh Reports. Poultry AND EGgS, AND HoNEY.. .. 1s. $0 d$. (1s, 2d.)

Cmd. 3168. Ninth Report. Toвacco .. .. 9 9d. (10d.)

Cmd, 3175. Tenth Report. Timber .. .. 99 9d (10d.)

Twelfth Report. Pigs and Pig Products .. $6 d . \quad$ (Sd.)

Sixteenth Report. Hides and Sirins . . . $\quad 6 d . \quad$ (7d.)

All prices are net; those in parentheses include postage.

Obtainable from the sale offices of

HIS MAJESTY'S STATIONERY OFFICE

LONDON : Adastral House, Kingsway, W.C.2.

MANCHESTER : York Street.
EDINBURGH: $t 20$, Ceorge Streel.

C.IRUIFF: 1 , St. Andrew's Crescent.

BELFAST: 1 5, Donegall 


\section{PUBLICATIONS ON EMPIRE TRADE.}

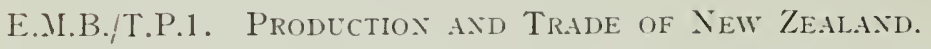

E.II.B./T.P.2. Production aNd Trade of Ceylon.

E.M.B. T.P.3. Prodection AND Trade OF CANADA.

E.M.B./T.P.4. Production axid Trade of Newholidelayo.

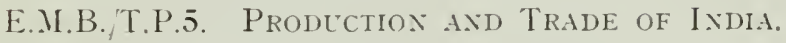

E.al B./T.P.6. Prodection aNid Trade of the Union of Solth Africa.

E.Ml.B./T.P.7. Prodiction AND Trade of Kexya and Uganda.

Price $2 d$. each net ( $3 d$. including postage).

Obtainable from the sale offices of

\section{HIS MAJESTY'S STATIONERY OFFICE}

London: Adastral House, Kingsway, WW.C.2. Edinburgh : I20, George Street.

Nanchester : York Street. Cardiff : r, St. Andrew's Crescent.

Belfast; $r_{5}$, Donegall Square West.

Or through any Bookseller.

74 Gulli 


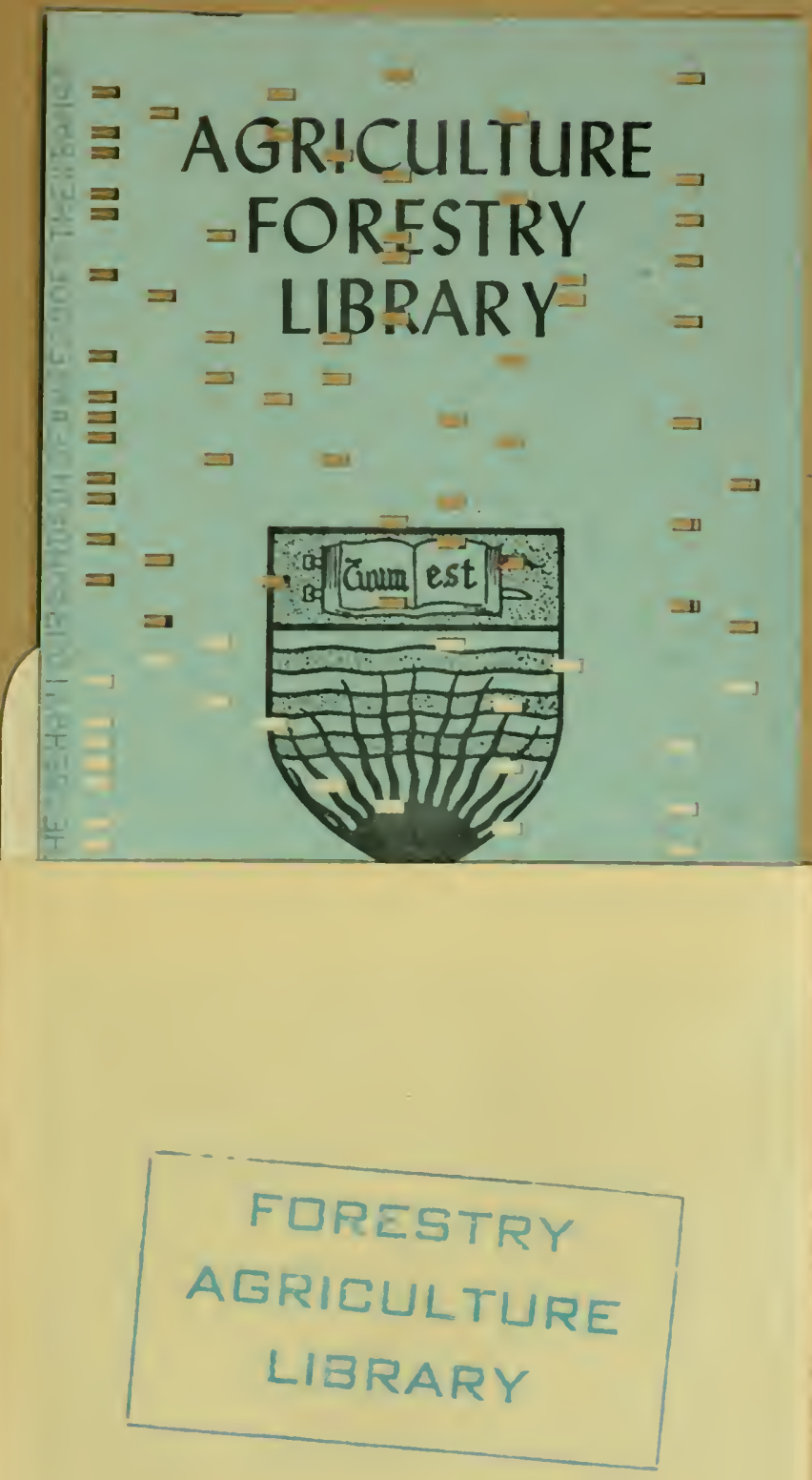


